\title{
Oxidation of 2-methylfuran and 2-methylfuran/ $n$-heptane blends: An experimental and modeling study
}

\author{
Rupali Tripathi ${ }^{\mathrm{a}, *}$, Ultan Burke ${ }^{\mathrm{b}}$, Ajoy K. Ramalingam ${ }^{\mathrm{b}}$, Changyoul Lee ${ }^{\mathrm{b}}$, \\ Alexander C. Davis ${ }^{c}$, Liming Cai ${ }^{\mathrm{a}}$, Hatem Selimc, Ravi X. Fernandes ${ }^{\mathrm{b}, \mathrm{d}}$, K. \\ Alexander Heufer ${ }^{b}$, S. Mani Sarathy ${ }^{c, *}$, Heinz Pitsch ${ }^{a}$ \\ ${ }^{a}$ Institute for Combustion Technology, RWTH Aachen University, 52056 Aachen, \\ Germany \\ ${ }^{b}$ Physico Chemical Fundamentals of Combustion, RWTH Aachen University, 52056 \\ Aachen, Germany \\ ${ }^{c}$ Clean Combustion Research Center, King Abdullah University of Science and \\ Technology, Thuwal 23955-6900, Saudi Arabia \\ ${ }^{d}$ Physikalisch Technische Bundesanstalt (PTB) Bundesallee 100, 38116 Braunschweig, \\ Germany
}

\section{Abstract}

There have been significant advances in understanding ignition behavior of oxygenated biofuels (mainly alcohols) and their blends with conventional fuel components. However, the oxidation behavior of lignocellulosic derived furanic compounds blended with hydrocarbons has received little attention. The present work is an experimental and numerical investigation of 2-methylfuran (2-MF) combustion and its blend with $n$-heptane. These results are compared with pure $n$-heptane results to better understand 2-MF reactivity. Ignition delay times of pure $2-\mathrm{MF}$ and the $2-\mathrm{MF} / n$-heptane (50/50

\footnotetext{
* Corresponding author:

Email address: r.tripathi@itv.rwth-aachen.de (Rupali Tripathi)
} 
2-MF $/ n$-heptane molar \%) blend in air were measured in three different facilities; a rapid compression machine and two different shock tubes. Experiments were performed in the temperature range of $861-913 \mathrm{~K}$ at a pressure of $20 \mathrm{bar}$ for stoichiometric pure 2-MF. The ignition delay times of $2-\mathrm{MF} / n$ heptane blends were measured in the temperature range of $672-1207 \mathrm{~K}$, at pressures of $10 \mathrm{bar}$ and $20 \mathrm{bar}$, and at equivalence ratios of $0.5,1.0$, and 1.5. A comprehensive chemical kinetic model containing low- to high-temperature chemistry of 2-MF and $n$-heptane was formulated based on a combination of available 2-MF and $n$-heptane mechanisms and available theoretical studies on 2-MF form literature. The developed detailed kinetic model was validated against the ignition delay data measured in this work as well as against high-temperature shock tube ignition delay, flame speed, and flame species data from literature to ensure the competence of the model. The proposed mechanism predicts the measured and literature data to a reasonable extent. To elucidate fuel specific oxidation pathways, reaction path analyses were performed at various conditions. Furthermore, sensitivity analyses on the ignition delay times were conducted and the dominant reaction pathways in the oxidation of pure and binary mixtures at high, intermediate, and low temperatures were identified. It is found that the competition between $n$ heptane and 2-MF for $\dot{\mathrm{OH}}$ radicals inhibits the consumption of $n$-heptane and promotes the consumption of 2-MF. This work provides the first insight into the global low-temperature oxidation behavior of a second generation furanic blended with a hydrocarbon. 
Keywords: 2-Methylfuran, n-Heptane, Shock tube, Rapid compression machine, Ignition delay, Kinetic model

\section{Introduction}

Hazardous effects of pollutant emissions from burning petro-diesel fuels have paved the way for development of cleaner combustion in engines. One probable way to address the challenge of emissions, is to blend oxygenated fuels with conventional fuel surrogates. Mixing of oxygenated fuels with hydrocarbons helps in reducing soot formation [1]. Among the available oxygenates, ethanol is widely used as an additive for gasoline and diesel fuels $[2-7]$ and characterized as the most suitable additive for spark-ignition (SI) engines. However, the ethanol blending with conventional fuels also increases the formation of other toxic pollutants like formaldehyde and acetaldehyde $[8,9]$. Other drawbacks associated with the use of ethanol are its lower vapor pressure and miscibility in water [10]. Compared to ethanol, 2-methylfuran (2-MF) has been identified as a new potential lignocellulosicderived biofuel [11]. Sudholt et al. [12] measured derived cetane numbers (DCNs) of several furanics and tetrahydrofuranics in an ignition quality tester. Based on its very low DCN of 8.9, compared to $n$-heptane with a DCN of 53.8, 2-MF was proposed as a promising SI engine fuel. Combustion characteristics of 2-MF have been throughly investigated in SI engines [11, 13-15]. These studies [11, 13-15] reveal that 2-MF offers significant advantages over gasoline and ethanol such as a higher energy density, a higher research octane 
number (RON), and lower hydrocarbon emissions. Although formaldehyde was found to be a major intermediate of combustion of $2-\mathrm{MF}$, its emission is much lower from 2-MF than that from ethanol and gasoline. 2-MF is derived from waste cellulose [16], has lower boiling point, and higher vapor pressure than that of ethanol [10]. 2-MF is negligibly soluble in water unlike ethanol, and hence is not contaminated by absorbing water from the atmosphere.

Ever since lignocellulosic biofuel production came into the picture, many experimental and numerical studies of 2-MF and other alkylated furans have been performed [17-43]. Somers et al. [17] measured the laminar burning velocities (LBVs) of 2-MF/air mixtures as a function of equivalence ratio $(\Phi)$. The measurements were carried out at atmospheric pressure and in the temperature range of $298-398 \mathrm{~K}$. LBVs were found to be controlled by the reaction of hydrogen with molecular oxygen at fuel rich conditions. On the other hand, under fuel lean conditions, oxidation of $\mathrm{CO}$ by $\dot{\mathrm{OH}}$ radical to produce $\mathrm{CO}_{2}$ and $\mathrm{H}$ radical was found equally important. In the same work, the ignition delay time measurements of $2-\mathrm{MF} / \mathrm{O}_{2} / \mathrm{Ar}$ mixtures were performed in a shock tube at equivalence ratios of $0.5,1.0$, and 2.0 , in the temperature range of $1200-1800 \mathrm{~K}$, and at atmospheric pressure. $\mathrm{H}$-abstraction from the side methyl group by $\dot{\mathrm{H}}$ was found to be the most important pathway in this temperature regime. Further, Ma et al. [25, 26] investigated low-pressure LBVs of 2-MF and 2-MF/iso-octane blends in a constant volume vessel with the help of high-speed schlieren photography at various temperatures and equivalence ratios. The LBVs of the blends were found to be somewhere in 
between those of pure 2-MF and pure iso-octane. The blended fuel flames were found to be less stable than iso-octane flames, but more stable than 2-MF flames at equivalence ratios lower than 1.0 at all tested temperatures.

Continuing the series of experimental measurements, Wi et al. [18], Uygun et al. [19], Eldeeb et al. [20], and Xu et al. [21], measured ignition delay times of $2-\mathrm{MF}$ behind reflected shock waves at $\Phi$ ranging from 0.25 to 2.0 , in the pressure range of $1.2-40 \mathrm{bar}$, and the temperature range of $800-2010 \mathrm{~K}$, with oxygen concentrations up to $20 \%$. The measured data was simulated using the high-temperature 2-MF model of Somers et al. [17]. The results demonstrate the pressure and dilution ratio dependence of measured 2-MF ignition delay times, which decreases with increasing pressure and decreasing dilution ratio. Concerning intermediate-temperature ignition delay measurements, Sudholt et al. [22] and Xu et al. [23] reported 2-MF experimental data in rapid compression machines at a temperature range of $824-1030 \mathrm{~K}$. Sudholt et al. [22] compared the RCM ignition delays of 2-MF with furan, 2-ethylfuran, and 2-butylfuran. The reactivity of alkylated furans was found to increase with increasing side chain length. Xu et al. [23] compared the RCM ignition delays of 2-MF with those of 2,5-dimethylfuran (2,5-DMF) and reported a comparable reactivity of 2-MF and 2,5-DMF under the studied conditions. A cross-over temperature was observed, below which 2,5-DMF reactivity was shown to be slightly higher and vice versa.

Furthermore, Tran et al. [24], in their series of works on furanics addressed the combustion of $2-\mathrm{MF}$ in a premixed low-pressure flame for stoichiometric 
and fuel rich mixtures. Mole fractions of a large number of reactants, products, and intermediates were identified and quantified in combination with electron-ionization molecular-beam mass spectrometry (EI-MBMS) and gas chromatography (GC) at pressures of 20 mbar and 40 mbar. In addition to the experimental work, a chemical kinetic mechanism of 2-MF was developed and validated [24]. Under measured conditions, ipso-addition yielding furan and $\mathrm{H}$-addition to the side chain carbon were identified as the main consumption pathways of 2-MF. Later, Cheng et al. [27] also reported the species profile measurements of $2-\mathrm{MF} / \mathrm{O}_{2} /$ Ar mixtures in a laminar flat flame burner. Recently, Alexandrino et al. [44] and Tran et al. [45] measured species profiles of 2-MF in a plug flow and a laminar flow reactor, respectively. A chemical kinetic model of 2-MF was also developed in the work of Tran et al. [45], based on theoretically calculated rate parameters of several reactions. High concentrations of several toxic species, such as formaldehyde, acrolein, methyl vinyl ketone, furfural, and phenol, were detected and experimental observations were backed with numerical simulations.

From a chemical kinetic perspective, several studies were performed to understand the pyrolysis behavior of 2-MF. Grela et al. [28] and Lifshitz et al. [29-31] studied the decomposition of 2-MF experimentally in a heated flow reactor and in a single pulse shock tube, respectively. Later, Liu et al. [32, 33] and Sendt et al. [34] studied the pyrolysis of 2-MF theoretically with the help of ab-initio quantum chemical methods. Several ab-initio calculations [3436] were also performed to calculate formation enthalpies, bond dissociation 
energies (BDEs), and rate parameters for a range of unimolecular decomposition reactions, confirming the presence of considerably weak $\mathrm{C}-\mathrm{H}$ bonds on the alkyl side-chain. The presence of weak $\mathrm{C}-\mathrm{H}$ bonds in 2-MF and 2,5-DMF offers an important site for abstraction by free radicals and are a key source of reactive hydrogen atoms. In the theoretical study of Somers et al. [37], the rate parameters and thermodynamic parameters of high-temperature specific reactions like $\beta$-scission, unimolecular decomposition, and $\mathrm{H}$-abstraction by $\dot{\mathrm{H}}$ and $\dot{\mathrm{C}} \mathrm{H}_{3}$ were presented. Concerning low-temperature oxidation, Davis et al. [46], in their computational work on 2-MF, gave insight on the lowtemperature alkene specific reaction pathways like Waddington elimination and Waddington concerted elimination reactions.

Despite extensive development at high to moderate temperatures [17-37], the chemical kinetics of 2-MF oxidation at lower combustion temperatures are not well known. There remains a need to characterize the combustion behavior of 2-MF at low temperatures because phenomena such as knock in SI engines and ignition in compression ignition (CI) engines are influenced by low-temperature reactions. 2-MF is a stable furanic compound, and that limits its reactivity at low temperatures, but practical engine applications would blend 2-MF with a hydrocarbon base fuel. The presence of more reactive species ( $n$-alkanes) in blends could initiate the oxidation of $2-\mathrm{MF}$ at low temperatures. A similar approach was used by Zhang et al. [47] to study the low-temperature oxidation of toluene by blending it with dimethyl ether.

With this motivation, the present work focuses on both experimental and 
numerical results for $2-\mathrm{MF}$ and $2-\mathrm{MF} / n$-heptane mixtures at various conditions. As per the author's knowledge, this is the first work providing insight into the low-temperature combustion behavior of 2-MF blended with hydrocarbons. Briefly, the sections of this paper include the following. Section 2 represents the experimental facilities used to measure the ignition delay times, followed by the development of the detailed kinetic model in section 3. The sections thereafter, include a comprehensive assessment of the model performance against measured experimental data as well as literature data. Then, a comparison of ignition characteristics of pure 2-MF with blended mixtures of $2-\mathrm{MF} / n$-heptane and pure $n$-heptane is presented, followed by a detailed chemical kinetic analysis of $2-\mathrm{MF}$ and the $2-\mathrm{MF} / n$-heptane blend oxidation.

\section{Experimental description}

\subsection{PCFC RWTH Aachen rapid compression machine}

The rapid compression machine (RCM) used during the course of this study has been described in detail previously [48]. It has a single piston configuration, with a variable volumetric ratio. This is possible through the interchange of the end walls resulting in the altering of the distance between the piston's face and the end wall at the top dead center position. The RCM is equipped with a heating system covering the reactor chamber. The system is controlled and monitored by 13 type- $\mathrm{T}$ thermocouples mounted along the reactor wall. This ensures a homogeneous initial temperature and also allows 
the RCM to study various initial temperatures (ambient up to $423 \mathrm{~K}$ ). The ability to operate the RCM at different initial temperatures is particularly important when studying non-volatile fuels with low-vapor pressures, where heating of the gaseous mixture maybe required, thereby preventing condensation. Creviced piston heads, optimized to the facility's geometry, are used for suppressing the formation of roll-up vortices. This ensures a homogeneous temperature field within the reactor core at the end of compression. The RCM has an estimated $15 \%$ variation in the measured ignition delay times and the experimental uncertainty in the compressed temperature is $\pm 5 \mathrm{~K}$ [49]. The pressure within the RCM is measured using a recessed and silicon coated PCB113B24 sensor. The compressed conditions were calculated using the compression/expansion routine in the Gaseq code [50]. 2-MF $(\geq 99.0 \%)$ was supplied by Sigma-Aldrich. Oxygen $(\geq 99.995 \%)$, argon $(\geq$ 99.996\%), and nitrogen ( $\geq 99.95 \%$ ) were supplied by Westfalen AG and Praxair. Mixtures were premixed in two $1 \mathrm{~L}$ stainless steel heated mixing vessels. The mixtures were allowed to mix for at least 30 minutes in order to ensure homogeneous mixing via gaseous diffusion.

Figure 1 presents a typical pressure trace obtained during the measurement of the ignition delay times presented here. Also highlighted in Fig. 1 is the definition used for the ignition delay time in all experiments, which is the time between the end of compression (time $=0$, when the piston has come to its final position or top dead center position) and the near instantaneous pressure increase caused by autoignition. All the reported experiments show 




Figure 1: Typical pressure trace obtained from the RCM, together with the definition of characteristic times. Experimental conditions: $\Phi=1.0$ in air 50/50 2-MF/n-heptane, $T_{c}$ $=712 \mathrm{~K}, P_{c}=10.2 \mathrm{bar}$, and $\tau_{\text {ign }}=37.1 \mathrm{~ms}$.

a near instantaneous pressure increase, defining ignition similar to the example in Fig. 1. Non-reactive experiments are taken concurrently with reactive experiments, where the $\mathrm{O}_{2}$ concentration is exchanged for similarly diatomic $\mathrm{N}_{2}$. This allows for the quantification of the facility effects occurring during the experiments. These effects can be considered, firstly, as the finite time taken to compress the gaseous mixture, i.e., the compression phase shown in Fig. 1, and secondly, as the facility effects post-compression (heat losses to the walls) occurring post-compression and up to ignition. An example of a non-reactive experiment used to account for the facility effects during simulations is shown in Fig. 1 (red line). In order to accurately include the change in pressure/temperature before and after compression, the non-reactive profile is converted into a normalized effective volume profile through the isentropic relationship between pressure and density, thereby allowing the calculation of the effective volume. This method of RCM simulation has been used 
previously in many studies [51-55] to simulate the various RCM facilities.

\subsection{SWL RWTH Aachen shock tube}

The SWL shock tube (ST) used during this study, has been discussed in detail by Heufer and Olivier [56]. In brief, it has an inner diameter of $140 \mathrm{~mm}$ and a total length of $15.5 \mathrm{~m}$. The large inner diameter helps to reduce the facility effects occurring due to shock attenuation, as discussed by Petersen and Hanson [57]. The relatively longer tube allows the ignition delay times to be accurately measured from $0.05-7 \mathrm{~ms}$ in a non-tailored interface mode. Aluminum diaphragms are used as separators in this facility, and the bursting mechanism utilized is the double-diaphragm technique. An intermediate pressure is applied to the volume between the two diaphragms and then, in order to cause the diaphragms to burst, this pressure is reduced through the expansion of the gas into a dump tank using an automatic solenoid activated valve. This ST has a heating system capable of heating the facility from ambient temperature up to $473 \mathrm{~K}$. The maximum working pressure of this ST is 1000 bar. The pressure is monitored during the experiments using a silicone coated Kistler603B pressure transducer. In total, there are eight Kistler 603B sensors, mounted axially along the tube, in order to measure the incident shock velocity during experiments. To calculate the reflected shock conditions, the initial pressure and temperature conditions are recorded and the reflected shock velocity is calculated. These parameters are then used as an input into the in-house shock dynamics code KASIMIR [58]. The ignition 




Figure 2: Typical end wall pressure traces obtained from the SWL ST and PCFC ST, showing the method of measuring the ignition delay time. Experimental conditions in SWL ST: $\Phi=1.0$ in air 50/50 2-MF $/ n$-heptane, $T_{5}=757 \mathrm{~K}, P_{5}=19.5 \mathrm{bar}$, and $\tau_{i g n}=$ $4.163 \mathrm{~ms}$. Experimental conditions in PCFC ST: $\Phi=1.0$ in air 50/50 2-MF/ $n$-heptane, $T_{5}=1089 \mathrm{~K}, P_{5}=19.5 \mathrm{bar}$, and $\tau_{i g n}=0.460 \mathrm{~ms}$.

delay time can be measured from the recorded pressure trace, Fig. 2. The uncertainty in the reflected shock temperature was calculated and is approximately $\pm 10 \mathrm{~K}[19]$. The gaseous test mixtures are prepared directly in the tube. The optimal mixing time for this procedure was found to be at least 1 hour, as has been reported in a previous publication [19].

\subsection{PCFC RWTH Aachen shock tube}

This facility is a newly designed ST facility and has been described in detail by Zhang et al. [59]. Briefly, it has an inner diameter of $63.5 \mathrm{~mm}$ and driver and driven section lengths of 3 and $4.1 \mathrm{~m}$, respectively. The tube is a similar design to the tube described by Darcy et al. [60] and Burke et al. [51]. The main design differences of this new facility are the incorporation of a curved driver section and a slightly reduced driven section length. The new facility uses four PCB113B24 pressure transducers, spaced axially along 
the tube, in order to measure the shock velocity and determine the shock attenuation. The shock velocity at the end wall (point of reflection) can be extrapolated from the three shock velocity measurements and this is then taken as the reflected shock velocity for further calculations. The reflected shock routine of Gaseq [50] is used to calculate the temperature and pressure of the gas behind the reflected shock.

The PCFC ST is equipped with a heating system covering the driven section, the diaphragm chamber and $25 \mathrm{~cm}$ of the driver section nearest the mid-section. Flexlec(R heating coils are used to heat the tube and they are controlled using ICon4848 thermocoax temperature controllers. Type-T thermocouples are used to measure the surface temperature along the tube, in order to provide input to the temperature controllers. This heating system is insulated using a fiberglass insulation. The heating system is split into seven sections along the tube, and each section is controlled by its individual heating coil and temperature controller as described above. There is an uncertainty of $\pm 0.5 \mathrm{~K}$ assigned to the use of type- $\mathrm{T}$ thermocouples. The maximum initial temperature possible is $423 \mathrm{~K}$. The ST is capable of measuring ignition delay times for the reflected shock pressures from approximately 550 bar and has a designed static working pressure of 500 bar. It can accurately measure ignition delay times from $0.1-2 \mathrm{~ms}$, and this can be increased to $7 \mathrm{~ms}$ with the use of tailored interface conditions. Mixtures are premixed using a stainless steel mixing vessel, which is internally coated using Teflon (PTFE), in order to prevent possible surface reactions with the 
reactive mixtures. In addition to this, the mixing vessel is equipped with a magnetically driven stirring fan which ensures that the mixtures prepared are homogeneous. The mixtures are prepared manometrically using partial pressures and are allowed to mix for at least 1 hour prior to testing.

Figure 2 outlines a typical pressure trace obtained from the PCFC ST. The ignition delay time for this facility has the same definition as in SWL $\mathrm{ST}$, which is the time between the arrival of the reflected shock wave at the measuring sensor and the time when the near instantaneous pressure increase is observed due to ignition of the fuel mixture (Fig. 2). The uncertainty of the PCFC ST is estimated to be $1.1 \%$ in the reflected shock temperature and $3.5 \%$ in the reflected shock pressure based on the approach given in the work of Zhang et al. [59].

However, ignition delay measurements might also be affected by inhomogeneities or other gas dynamic effects. These effects are difficult to quanitify directly, but can result in a larger scatter of ignition delay times compared to the case where only the variation in pressure and temperature would influence the ignition process. An estimate for these uncertainties is provided by comparing the results of different facilities measured at the same conditions, which revealed that a variation of ignition delay times within $\pm 20 \%$ can be expected for different shock tube facilities [53]. This possible scatter is reflected by the error bars in the subsequent figures. 


\section{Kinetic model development}

The proposed chemical kinetic model, consisting of 883 species and 7872 reactions (forward and backward counted separately), was built hierarchically upon the $\mathrm{C}_{0}-\mathrm{C}_{4}$ base model of Blanquart et al. [61]. The base mechanism has been extensively validated [62-64] and contains the relevant chemistry needed to describe the oxidation of $\mathrm{C}_{0}-\mathrm{C}_{4}$ species. A sub-model of $n$-heptane, along with the $\mathrm{C}_{5}$ and $\mathrm{C}_{6}$ chemistry, was taken from the most recent optimized dodecane model of Cai et al. [65]. For the combustion of aromatic species, e.g. benzene, toluene, and phenol, the polycyclic aromatic hydrocarbon (PAH) mechanism of Narayanaswamy et al. [62] was incorporated in the present model. Regarding 2-MF specific reactions, a high-temperature specific submodel was adopted from the 2,5-DMF mechanism of Somers et al. [66]. The rate constants for unimolecular decomposition reactions, $\beta$-scission reactions, and H-abstraction reactions by $\dot{\mathrm{H}}$ and $\dot{\mathrm{C}} \mathrm{H}_{3}$ were extensively revised on the basis of the theoretical study of Somers et al. [37]. Several novel pathways along with their calculated rate parameters, for the consumption of 2-MF fuel radicals were adopted from the recent work of Tran et al. [45]. Additionally, a low-temperature specific sub-model of 2-MF was developed as a part of this research work and combined with the base mechanism. A detailed explanation on the low-temperature specific sub-model of 2-MF along with its structure and bond characteristics is provided in this section. 


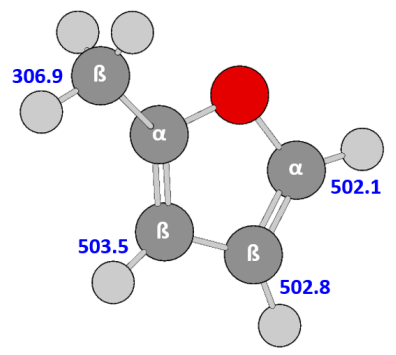

Figure 3: Structure and $\mathrm{C}-\mathrm{H}$ bond dissociation energies $(\mathrm{kJ} / \mathrm{mol})$ of 2-MF [35].

\subsection{2-MF structure and bond characteristics}

2-MF is an oxygenated cyclic diene molecule and consists of four $\mathrm{C}$ atoms and one $\mathrm{O}$ atom in the ring along with one methyl side chain at the carbonsite in position $\alpha$ to the $\mathrm{O}$ atom. The structure and $\mathrm{C}-\mathrm{H}$ BDEs of 2-MF are shown in Fig. 3. The $\beta$ primary $\mathrm{C}-\mathrm{H}$ bond is the weakest bond among all the $\mathrm{C}-\mathrm{H}$ bonds in 2-MF, which is comparable to the allylic $\mathrm{C}-\mathrm{H}$ bond of 1-butene ( 344 kJ/mol) [67]. According to the theoretical study of Simmie et al. [35], the ring $\mathrm{C}-\mathrm{H}$ bonds possess very high BDEs $(\sim 503 \mathrm{~kJ} / \mathrm{mol})$ because of the unsaturated nature of the cycle, which is even stronger than the $\mathrm{C}-\mathrm{H}$ bonds in benzene $(\sim 412 \mathrm{~kJ} / \mathrm{mol})$ [68]. Hence, H-abstraction from the ring carbons in 2-MF is much less energetically favored than that from ring carbons of aromatic hydrocarbons. However, double bonds in the ring offer attractive sites for the addition of radical species.

\subsection{General features of 2-MF low-temperature sub-model}

The present sub-model of 2-MF is based on the basic understanding of unsaturated cyclic compounds [46, 69-71] and alkenes [72-76] chemistry. 
The rate parameters were adopted preferentially from calculated studies, and where there is a of lack of calculated rate parameters, analogies with structurally similar fuel components were used to assign the rate for a particular reaction. Alkene specific reactions, co-oxidation reactions of 2-MF and $n$-heptane, and other incorporated reactions and modifications in the model are described in the following sub-sections.

\subsubsection{Alkene specific reactions}

With two unsaturated bonds, 2-MF can undergo radical addition to these bonds similar to other alkenes [72-76]. Bierbach et al. [77] in their study reported that $\dot{\mathrm{O}} \mathrm{H}$ addition to the ring is the dominant initiation pathway of 2-MF oxidation at lower temperatures, followed by the ring opening of the furan ring instead of the addition of $\mathrm{O}_{2}$. Later, Davis et al. [46] revealed that the formed adduct, after $\dot{\mathrm{OH}}$ addition to 2-MF, can further decompose via hydrogen migration (HM), concerted elimination (CE), Waddington elimination (WE), and Waddington concerted elimination (WCE) reactions. In order to investigate the nature of radical addition to 2-MF a low-temperature sub-model of 2-MF was developed on the basis of the computational study of Davis et al. [46]. The developed sub-model incorporates all the proposed pathways of 2-MF/ÖH adducts (MF22OH3J and MF25OH4J), dominantly

formed at $\alpha$ sites of the 2-MF ring. Figure 4 gives examples of these kind of reactions for MF25OH4J. 


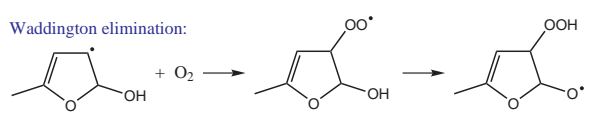

Waddington concerted elimination:
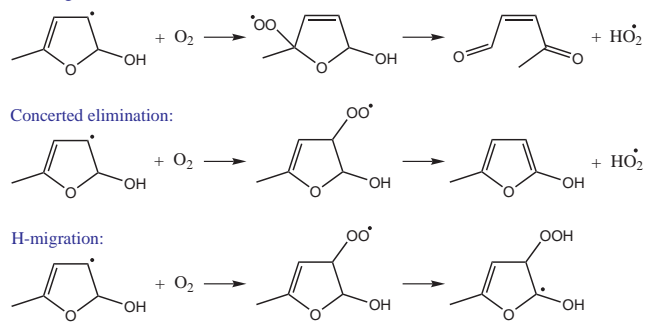

Figure 4: Alkene specific low-temperature reactions of 2-MF/ÖH adduct (MF25OH4J).

\subsubsection{Co-oxidation reactions}

The importance of co-oxidation reactions, in which fuel radicals generated from one fuel component abstract H-atom from other fuels, has been highlighted in several studies [69, 71]. For two significantly different fuels, 2-MF (unsaturated cyclic ether) and $n$-heptane (acyclic alkane), co-oxidation reactions may be unimportant at higher temperatures, because consumption of $n$-heptane mainly takes place at lower temperatures and 2-MF is relatively unreactive in this temperature regime. Moreover, due to the presence of $n$ heptane in the blend, when the pool of small radicals (e.g. ÖH) develops, $\mathrm{H}$-abstraction from 2-MF by these radicals or $\mathrm{OH}$-radical addition to 2-MF may become significant. Furthermore, at very low temperatures, hydrogen abstraction from 2-MF by the radicals generated from the low-temperature oxidation of $n$-heptane, e.g. alkylhydroperoxy (ROO), might also take place. Assessment of the importance and unimportance of the co-oxidation reactions for the blend of $2-\mathrm{MF}$ and $n$-heptane is vague and needs to be investigated 
further. A set of co-oxidation reactions between intermediate species formed in the oxidation of $2-\mathrm{MF}$ and the species of $n$-heptane is part of the current model and is presented in Fig. 5. Rate constants of these co-oxidation reactions were estimated on the basis of co-oxidation reactions of toluene and $n$-heptane, explained in the work of Andrae et al. [69, 70].

\subsubsection{Other incorporated reactions and modifications}

In addition to the alkene specific low-temperature reactions and co-oxidation reactions of $2-\mathrm{MF}$ and $n$-heptane, several other reactions and modifications were included in the present model, which are summarized as follows:

- In order to assess the importance of low-temperature specific chemistry, reaction of 2-furanylmethyl radical $\left(\mathrm{F} 2 \dot{\mathrm{C}} \mathrm{H}_{2}\right)$ with $\mathrm{O}_{2}$ was incorporated (Fig. 6). Rate parameters for this reaction were adopted from the quantum calculation work of Tran et al. [45].

- Rate constants for $\mathrm{H}$-abstraction reactions by $\dot{\mathrm{HO}}_{2}$ were taken from the 2,5-DMF mechanism of Somers at al. [66]. For improving the performance of the model, these rate constants were divided by a factor of two, within the uncertainty limit of 4-5, as assigned by Somers et al. [66].

- Somers et al. [66] calculated the rates of $\dot{\mathrm{OH}}$ addition to the $\alpha$-carbon of 2,5-DMF, based on the CBS-APNO and G3 calculations of the reactants and transition states. These rates were divided by a factor of two 
(within an uncertainty limit of 3), and adopted for the $\dot{\mathrm{O}} \mathrm{H}$ addition to the $\alpha$-carbon sites of $2-\mathrm{MF}$ for the improved agreement of the model against the experimental measurements. However, unlike in 2,5-DMF, 2-MF has two different $\alpha$ sites, $\alpha$-secondary and $\alpha$-tertiary carbon sites. Davis et al. [46] in their quantum calculation work on 2-MF, reported comparable energy barriers for the formation of $2-\mathrm{MF} / \dot{\mathrm{O}} \mathrm{H}$ adducts at these sites. Hence,the same rate parameters for the $\dot{\mathrm{O}} \mathrm{H}$ addition at both the $\alpha$-secondary and $\alpha$-tertiary carbons of $2-\mathrm{MF}$, were considered in the present model. The rate parameters for the addition of $\dot{\mathrm{OH}}$ to the $\beta$-carbon centers of $2-\mathrm{MF}$ were taken from the quantum calculation work of Davis et al. [46].

The developed reaction mechanism consists of all the proposed high- and low-temperature pathways of 2-MF oxidation. Thermochemical data for the species considered in the mechanism were preferentially adopted from the quantum calculation work of Somers et al. [37] and Tran et al. [45]. For the species involved in the developed low-temperature sub-model of 2-MF, thermochemical parameters were taken from the quantum calculation study of Davis et al. [46]. Thermochemical properties of most of the 2-MF specific species were found to be available in the aforementioned studies. For novel smaller species appearing in the oxidation of 2-MF, where theoretical calculations were not available, thermochemical properties were calculated using the THERM program [78], which uses the group additivity method of Benson et al. [79]. Revised group additivity values proposed by Burke et 
al. [80] were considered for these calculations. Transport parameters were calculated using the reaction mechanism generator package of Green et al. [81]. Thus having $\mathrm{C}_{0^{-}} \mathrm{C}_{7}$ and low- to high-temperature chemistry of 2-MF, the current model provides a good simulation of $2-\mathrm{MF}$ and $2-\mathrm{MF} / n$-heptane data. The complete mechanism along with the thermochemical and transport properties is available in the Supplementary material.



Figure 5: Co-oxidation reactions of 2-MF and its intermediate species with $n$-heptane and its intermediate species.

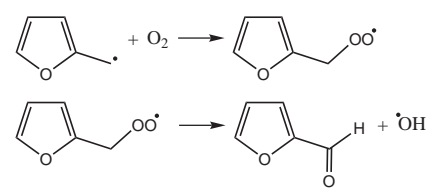

Figure 6: Addition of $\mathrm{O}_{2}$ to 2-furanylmethyl radical.

\section{Results and discussion}

The current section assesses the predictive capability of the developed mechanism by comparing the numerical simulation results against the experimental data sets obtained from various combustion reactors. The validation cases focus on the oxidation of $2-\mathrm{MF}$ and the $2-\mathrm{MF} / n$-heptane blend, and 
Table 1: List of validation cases considered in the present work for 2-MF.

\begin{tabular}{|c|c|c|c|c|c|}
\hline Species & Reactor & $\mathrm{T}[\mathrm{K}]$ & $\begin{array}{c}\text { Conditions } \\
\mathrm{P}[\mathrm{bar}]\end{array}$ & $\phi$ & References \\
\hline \multicolumn{6}{|l|}{ Ignition delay time } \\
\hline 2-MF/ $n$-heptane & $\begin{array}{l}\text { Rapid compression } \\
\text { machine }\end{array}$ & $600-1000$ & $10.0-20.0$ & $0.5-1.5$ & this work \\
\hline 2-MF / $n$-heptane & Shock tube & $820-1300$ & 20.0 & 1.0 & this work \\
\hline $2-\mathrm{MF}$ & $\begin{array}{l}\text { Rapid compression } \\
\text { machine }\end{array}$ & $750-900$ & 20.0 & 1.0 & this work \\
\hline $2-\mathrm{MF}$ & Shock tube & $820-1215$ & 40.0 & 1.0 & Uygun et al. [19] \\
\hline $2-\mathrm{MF}$ & $\begin{array}{l}\text { Rapid compression } \\
\text { machine }\end{array}$ & $833-909$ & 20.0 & 1.0 & Sudholt et al. [22] \\
\hline 2-MF & Shock tube & $1200-1800$ & 1.0 & $0.5-2.0$ & Somers et al. [17] \\
\hline $2-\mathrm{MF}$ & Shock tube & $1120-1700$ & $1.3-10.8$ & $0.25-2.0$ & Wi et al. [18] \\
\hline $2-\mathrm{MF}$ & Shock tube & $977-1500$ & $1.3-12.2$ & $0.5-2.0$ & Eldeeb et al. [20] \\
\hline $2-\mathrm{MF}$ & Shock tube & $1150-2010$ & $1.2-16.0$ & 1.0 & $\mathrm{Xu}$ et al. [21] \\
\hline $2-\mathrm{MF}$ & $\begin{array}{l}\text { Rapid compression } \\
\text { machine }\end{array}$ & $824-1041$ & $16.0-30.0$ & 1.0 & $\mathrm{Xu}$ et al. $[23]$ \\
\hline \multicolumn{6}{|c|}{ Laminar burning velocity } \\
\hline 2-MF & Heat flux burner & $298-395$ & 1.0 & $0.55-1.65$ & Somers et al. [17] \\
\hline $2-\mathrm{MF}$ & $\begin{array}{l}\text { Constant volume ves- } \\
\text { sel }\end{array}$ & $333-393$ & 1.0 & $0.6-1.1$ & Ma et al. $[25,26]$ \\
\hline \multicolumn{6}{|l|}{ Species profile } \\
\hline $2-\mathrm{MF}$ & $\begin{array}{l}\text { Laminar flat flame } \\
\text { burner }\end{array}$ & 333 & $0.02-0.04$ & $1.0-1.7$ & Tran et al. [24] \\
\hline $2-\mathrm{MF}$ & $\begin{array}{l}\text { Laminar flat flame } \\
\text { burner }\end{array}$ & 298 & 0.04 & $0.8-1.5$ & Cheng et al. [27] \\
\hline $2-\mathrm{MF}$ & Plug flow reactor & $800-1400$ & 1.0 & $0.02-3.33$ & Alexandrino et al. [44] \\
\hline 2-MF & Laminar flow reactor & $730-1170$ & 1.0 & $0.5-2.0$ & Tran et al. [45] \\
\hline
\end{tabular}

include (i) ignition delay times measured in STs and RCMs, spanning wide ranges of temperatures, pressures, and equivalence ratios, (ii) laminar burning velocities obtained at various pressures and temperatures, (iii) species profiles of laminar flat flames, and (iv) species profiles measured in flow reactors. The developed chemical kinetic mechanism has been used to simulate these combustion properties using the FlameMaster [82] code, along with the appropriate reactor modules. Table 1 lists the validation cases considered in the present study, which are further described in detail in the following subsections. 


\subsection{Validation tests 2-methylfuran/n-heptane blends}

The ignition delay results obtained for the oxidation of 2-MF/n-heptane blends are described in this section. All experimental results can be found in the Supplementary material (Table S1).

\subsubsection{Effect of pressure on ignition delay time}

The effect of pressure on the ignition delay of $2-\mathrm{MF} / n$-heptane mixtures was investigated by varying the pressure from 10 bar to 20 bar. Figure 7

shows the measured and the calculated ignition delays of $2-\mathrm{MF} / n$-heptane blends at pressures of 10 bar and 20 bar. In order to assess the facility-tofacility variation in the ST experimental data, ST experiments at PCFC RWTH Aachen were carried out at the same conditions as those employed at SWL RWTH Aachen, i.e. $\phi=1$ and $\mathrm{P}=20$ bar. It can be seen in Fig. 7 that experimental measurements from both the facilities agree very well. Due to shock attenuation, which is caused by boundary layer effects and by non-ideal bursting of diaphragms [57], a pressure rise $(\mathrm{dP} / \mathrm{dt})$ is typically observed in ST experiments irrespective of the temperature regimes. However, this is more relevant for the conditions with longer ignition delay times $(>1 \mathrm{~ms}$ ), where the pressure rise affects the ignition event. However, for shorter ignition delay times, this pressure increase does not play a significant role. The rates of pressure change $(\mathrm{dP} / \mathrm{dt})$ in the SWL and PCFC shock tube are $5 \% / \mathrm{ms}$ and $8 \% / \mathrm{ms}$ respectively. It can be seen in Fig. 7 that the SWL ST measurements are at lower temperatures, hence longer ignition delays, 
in comparison to the PCFC ST measurements. Since simulations including $5 \% / \mathrm{ms}$ and $8 \% / \mathrm{ms}$ are very similar for the tested temperature range (see Fig. S1 of the Supplementary material), for clarity only numerical simulations including $8 \% \mathrm{dP} / \mathrm{dt}$ are presented in Fig. 7. In order to account for RCM facility effect of heat loss to the walls, effective volume histories were used in the simulations, which were derived from non-reactive pressure traces from experiments. A detailed explanation on the simulations including facility effects in ST and in RCM has been provided in detail elsewhere [19, 64, 83]. The solid lines correspond to the constant volume, adiabatic numerical simulations and the dashed lines correspond to the simulations including facility effects of ST and RCM.

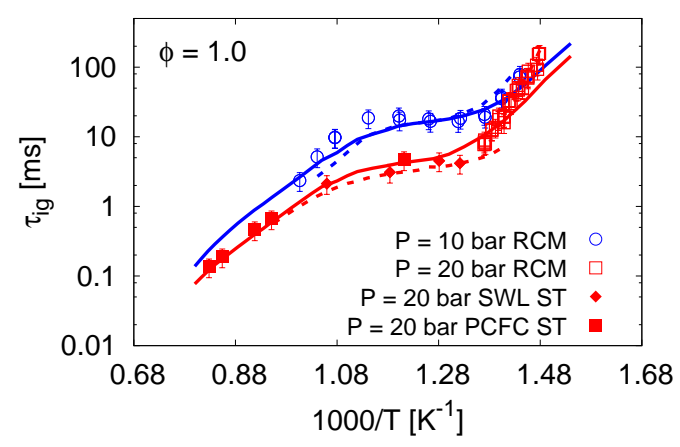

Figure 7: Effect of pressure on ignition delay times of $2-\mathrm{MF} / n$-heptane blend in RCM and in ST. Symbols - experiments; solid lines - numerical simulations at constant volume; dashed lines - numerical simulations including facility effects.

The model accurately predicts the ST and the RCM ignition delay data at the pressure of 20 bar. However, data points obtained in the RCM at the pressure of 10 bar are under-predicted in the temperature range of $833-926 \mathrm{~K}$ 
$(1.20-1.081 / \mathrm{K})$. The blend of $2-\mathrm{MF} / n$-heptane exhibits a negative temperature coefficient (NTC), which is well reproduced by the model as well. The 2-MF / $n$-heptane blend shows strong pressure dependence at intermediate temperatures ranging from $725 \mathrm{~K}$ to $925 \mathrm{~K}(1.38-1.081 / \mathrm{K})$. With an increase in pressure, the effective concentration of reactants increases and ignition becomes faster. At lower temperatures, pressure change causes a negligible impact on ignition. This negligible impact of pressure change on ignition at lower temperatures has been observed for hydrocarbon fuels too [84-86]. The present model reproduces the experimentally observed trend of increasing pressure on ignition delays reasonably well.

\subsubsection{Effect of equivalence ratio on ignition delay time}

Figures 8 and 9 depict the effect of equivalence ratio on ignition delay times of $2-\mathrm{MF} / n$-heptane blends at pressures of 10 bar (Fig. 8) and 20 bar (Fig. 9). The effect of equivalence ratio on ignition delay times was determined by measuring ignition delay times for fuel lean, stoichiometric, and fuel rich mixtures $(\phi=0.5,1$, and 1.5). For both pressures of $10 \mathrm{bar}$ and 20 bar, adiabatic simulations strongly under-predict the experimental data sets and simulations including facility effects improve the agreement for all three equivalence ratios of $0.5,1$, and 1.5 . The variable volume RCM simulations indicate that at a pressure of $10 \mathrm{bar}$, the model under-predicts ignition delay by up to a factor of 3 in the intermediate temperature range of $800-952 \mathrm{~K}(1.25-1.051 / \mathrm{K})$. Below $800 \mathrm{~K}(1.251 / \mathrm{K})$, fuel-rich and stoichio- 
metric mixtures are predicted reasonably well, whereas, fuel lean mixtures are strongly over-predicted across the studied temperature range. In their work on CFD simulations for the $n$-heptane ignition, Mittal et al. [87] reported that the variable volume simulations lead to a higher pressure rise in the first stage ignition delays, which consequently leads to shorter total ignition delay. It was also observed that this discrepancy is fuel and pressure dependent and decreases with an increase in the pressure. Hence, the observed under-prediction of experiments by variable volume RCM simulations is due to the uncertainties arising from simulations including RCM facility effects, as reported by Mittal et al. [87] and over-prediction is associated with the uncertainties in reaction kinetics. At a pressure of 20 bar (Fig. 9), for all three equivalence ratios, a satisfactory agreement between numerical simulations and measured data is observed.

Experimental data shows that an increase in fuel concentration leads to an increase in reactivity (or a decrease in the ignition delay times) for both pressures of 10 and 20 bar at all temperatures (Figs. 8 and 9). In order to gain more insight into the dependency of ignition delays on equivalence ratio, a reaction path analysis was performed at a temperature of $1000 \mathrm{~K}$ and at a pressure of 10 bar for all the three equivalence ratios (see Fig. S2 of the Supplementary material). It should be noted that the branching ratio between $\mathrm{H}$-abstraction reaction by $\dot{\mathrm{OH}}$ and $\dot{\mathrm{O}} \mathrm{H}$ addition reaction is important, as the former produces one $\dot{\mathrm{O}} \mathrm{H}$ radical by the reaction of the formed $\mathrm{F} 2 \dot{\mathrm{C}} \mathrm{H}_{2}$ radical with $\mathrm{HO}_{2}$ and the latter consumes an $\dot{\mathrm{O}} \mathrm{H}$ radical. A comparable branching 


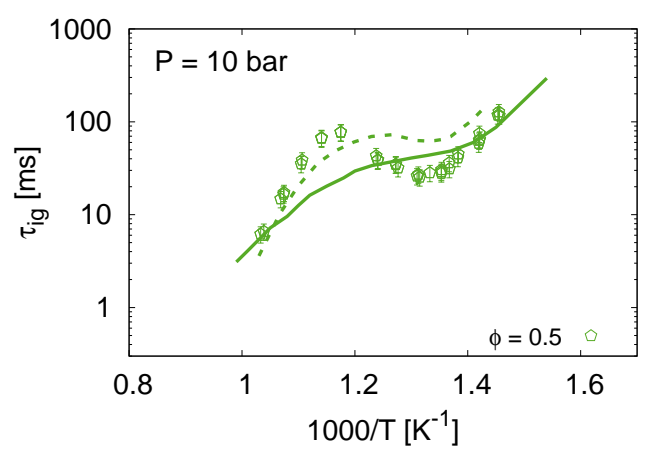

(a)

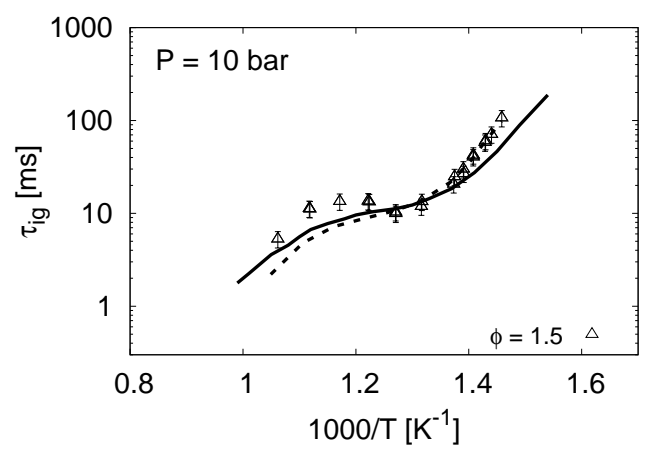

(c)



(b)

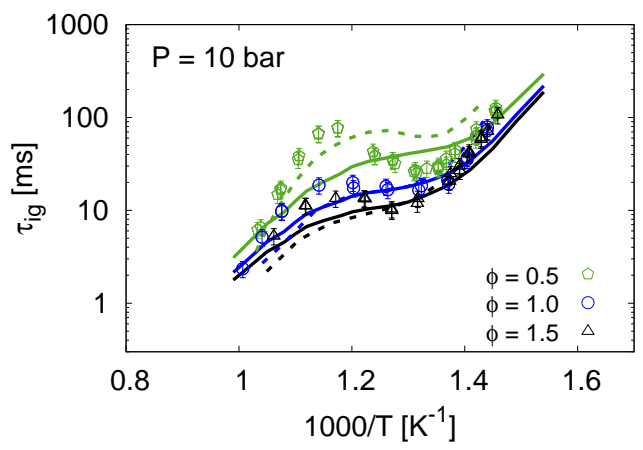

(d)

Figure 8: Ignition delay times of $2-\mathrm{MF} / n$-heptane blend in RCM at 10 bar. Symbols experiments; solid lines - numerical simulations at constant volume; dashed lines - numerical simulations including facility effects. Figure (a) $\phi=0.5$; (b) $\phi=1.0$; (c) $\phi=1.5$; (d) equivalence ratio dependence.

ratio was observed for all the three equivalence ratios, hence the concentration of the fuel is the decisive factor for its reactivity and the mixture with higher fuel concentration has higher reactivity. This is because at the lower temperatures studied here, increasing fuel concentration results in increased radical production via fuel $+\mathrm{HO}_{2}$ = fuel radical $+\mathrm{H}_{2} \mathrm{O}_{2}$ followed by $\mathrm{H}_{2} \mathrm{O}_{2}$ $+\mathrm{M}=\mathrm{OH}+\mathrm{OH}+\mathrm{M}$, and therefore reactivity increases with equivalence 


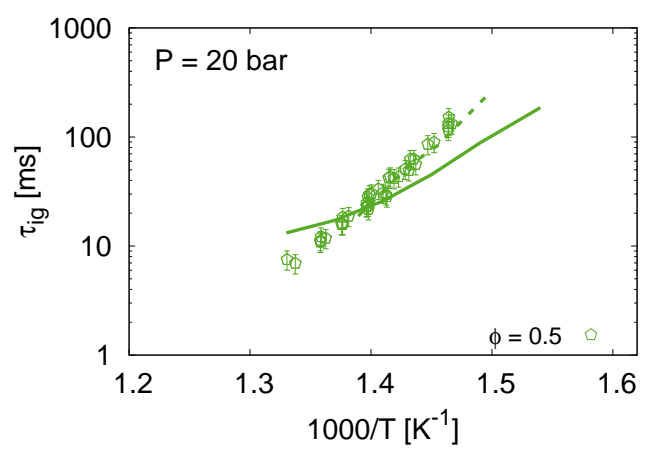

(a)

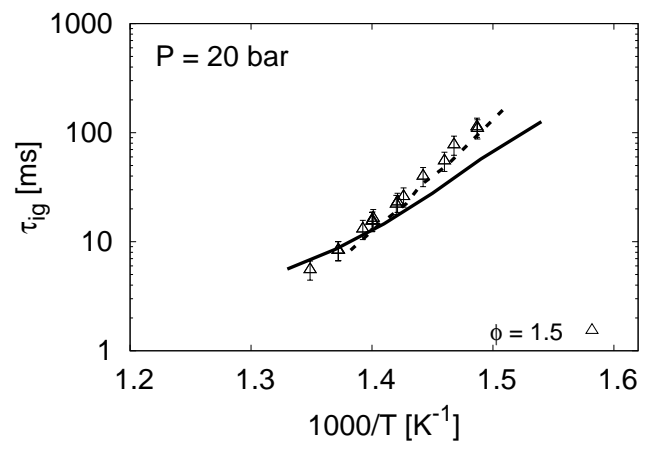

(c)

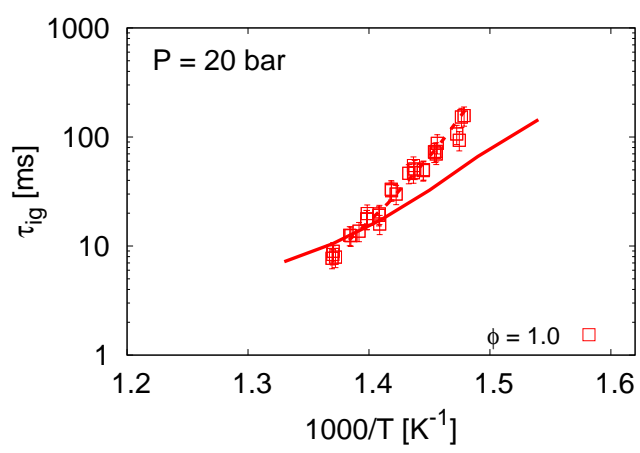

(b)

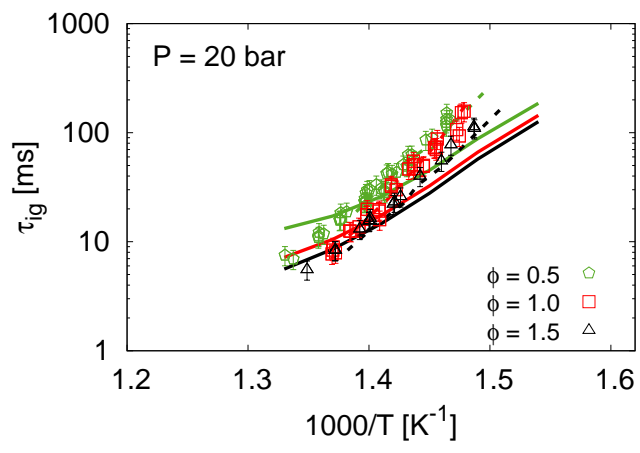

(d)

Figure 9: Ignition delay times of $2-\mathrm{MF} / n$-heptane blend in RCM at 20 bar. Symbols experiments; solid lines - numerical simulations at constant volume; dashed lines - numerical simulations including facility effects. Figure (a) $\phi=0.5$; (b) $\phi=1.0$; (c) $\phi=1.5$; (d) equivalence ratio dependence.

ratio [88]. It should be noted that our observations are limited to the temperature range studied (i.e., below $1000 \mathrm{~K}$ ) here. At higher temperatures (e.g., $1200 \mathrm{~K}$ ), ignition delay is governed by the chain branching reaction $\mathrm{H}$ $+\mathrm{O}_{2}=\mathrm{OH}+\mathrm{O}$. Under such conditions, increasing equivalence ratio for fuel/air mixtures (i.e., increasing fuel concentration) scavenges $\mathrm{H}$ atoms via fuel $+\mathrm{H}=$ fuel radical $+\mathrm{H}_{2}$, thereby reducing reactivity. 
In order to see the importance of the developed 2-MF low-temperature sub model, numerical simulation results of the stoichiometric 2-MF/n-heptane blend at a pressure of 20 bar, with and without low-temperature sub-model are presented in Fig. 10. The developed 2-MF low-temperature sub-model includes Waddington elimination reactions, Waddington concentration elimination reaction, H-migration reactions, concerted elimination reactions, and co-oxidation reactions. It is evident from Fig. 10 that the inclusion of these reactions in the sub-model increases its reactivity and leads to shorter ignition delay. This effect was observed to be more pronounced below $685 \mathrm{~K}$ $(1.461 / \mathrm{K})$. Hence, the newly added reactions are indeed essential for the better performance of the model.

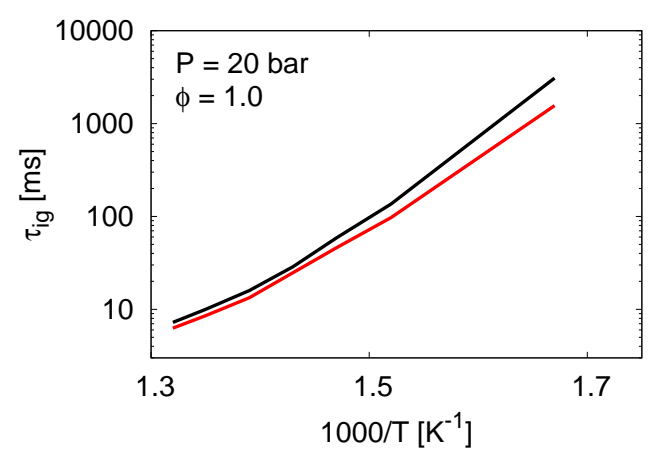

Figure 10: Comparison of simulation results with and without the developed 2-MF lowtemperature sub-model. Black line - numerical simulations without 2-MF low-temperature sub-model; red line - numerical simulations with 2-MF low-temperature sub-model.

\subsection{Validation tests pure 2-methylfuran}

The numerical simulations are now compared against the ignition delays of pure 2-MF. The performance of the model against the newly measured ig- 
nition delays of stoichiometric 2-MF/oxidizer/diluent mixtures at $\mathrm{P}=20$ bar, the ignition delays measured in an ST by Uygun et al. [19] at P $=40$ bar, and against those measured by Sudholt et al. [22] at a pressure of 20 bar in an RCM, is presented in Fig. 11. Simulations at constant volume are shown as line plots in Fig. 11, while simulations including ST and RCM facility effects are represented by dashed lines. The newly measured RCM data set matches well with the data set of Sudholt et al. [22]. Unlike its blend with $n$-heptane, pure 2-MF does not possess NTC behavior. This is because of its inhibited reactivity and the lack of conventional low-temperature chain-branching due to its stable unsaturated structure. The predicted ignition delays compare well with the experimental values with the exception of those below $890 \mathrm{~K}$ $(1.121 / K)$. Both ST and RCM data sets are over predicted by the model at lower temperature regimes. The model accurately predicts the observed trend of decrease in ignition delay time with an increase in pressure and non NTC behavior of pure 2-MF.

In addition to the aforementioned experimental data, the present model was also compared against other experimental data sets taken from the literature. Results of these validation tests are shown in Figs. S3-S11 of the Supplementary material. More importantly, these literature data sets include ignition delay measurements in STs and $\operatorname{RCM}[17,18,20,21,23]$ (Figs. S3-S6), laminar burning velocity measurements from two different facilities $[17,25,26]$ (Fig. S7), and 2-MF species profiles measured in lowpressure flames and flow reactors [24, 27, 44, 45] (Figs. S8-S11). In general, 


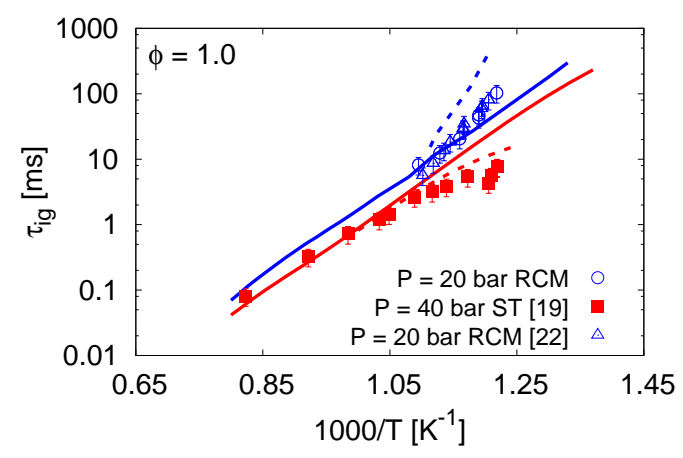

Figure 11: Ignition delay times for pure 2-MF in RCM and in ST. Symbols - experiments; solid line - numerical simulations at constant volume; dashed lines - simulations including facility effects.

a satisfactory performance of the model against the ignition delay and laminar burning velocity experiments is observed. However, big discrepancies are noticed with respect to species profile data sets.

\subsection{Comparison of 2-MF, 2-MF/n-heptane blend, and n-heptane oxidation}

In order to explore the effect of adding $n$-heptane on the 2-MF reactivity, ignition delays of pure $2-\mathrm{MF}$, the $2-\mathrm{MF} / n$-heptane blend, and pure $n$-heptane [59] are compared here. Ignition delay measurements of stoichiometric $n$-heptane/air mixtures [59] serve as additional targets for model validation. Figure 12 presents the measured and the calculated ignition delays for the three cases at an equivalence ratio of 1.0 and at a pressure of 20 bar. The performance of the model against pure $2-\mathrm{MF}$ and $2-\mathrm{MF} / n$ heptane blends has been discussed in the previous section. The numerical simulations for pure $n$-heptane predict the measurements within reasonable uncertainty at all temperatures. 


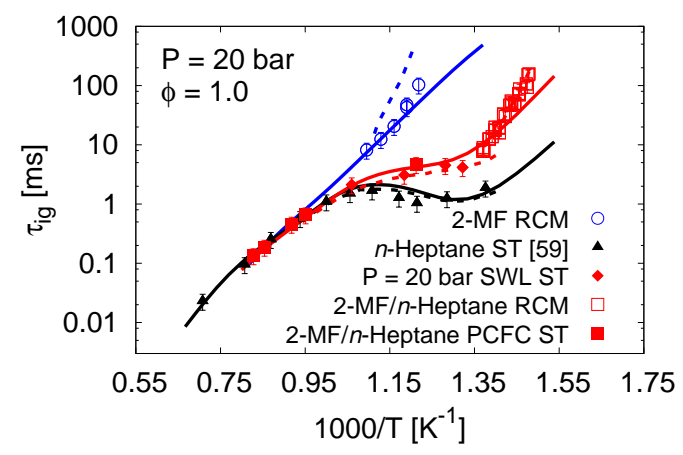

Figure 12: Comparison of 2-MF, 2-MF/n-heptane blend, and $n$-heptane ignition at $\phi=$ 1 and $\mathrm{P}=20$ bar. Solid symbols - ST data; open symbols - RCM data; solid lines numerical simulations at constant volume; dashed lines - numerical simulations including facility effects.

Among the three cases, pure 2-MF is the least reactive and pure $n$-heptane is the most reactive. The reactivity of the $2-\mathrm{MF} / n$-heptane blend lies in between that of pure 2-MF and pure $n$-heptane. The difference in reactivities of pure $2-\mathrm{MF}$, the blend of $2-\mathrm{MF} / n$-heptane, and pure $n$-heptane is found to be temperature-dependent. The difference is more pronounced at lower temperatures, and it gets relatively smaller for the intermediate temperature range. Indeed, the ignition delay curves appear to be merging for higher temperatures beyond $1250 \mathrm{~K}(0.81 / \mathrm{K})$. At lower temperatures, the ignition of the $2-\mathrm{MF} / n$-heptane blend depends on both of its constituents. The ignition of the blend is promoted as a result of low-temperature branching of $n$-heptane oxidation. Conversely, at intermediate to high temperatures, the decrease in the difference of reactivity for these fuels is because of this diminishing $n$-heptane specific degenerate branching. Another key observation from Fig. 12 is that the blend exhibits NTC behavior, which is lesser 
pronounced than that in pure $n$-heptane. This lesser pronounced NTC behavior in the blend is because of the lower concentration of $n$-heptane in the blend $(50 \%)$ in comparison to that in pure $n$-heptane $(100 \%)$. The presence of 2 -MF inhibits the $n$-heptane chemistry by competing with $n$-heptane for radicals required to initiate its oxidation at these temperatures. Pure 2-MF does not show NTC behavior because of the presence of a relatively unreactive unsaturated ring. A low-temperature degenerate branching as it occurs in the oxidation of $n$-heptane is structurally not possible in 2-MF. The absence of NTC behavior in the oxidation of pure 2-MF explains its very high octane sensitivity (RON-MON) of 17 [10]. As described by Mehl et al. [89], gasoline fuels with high octane sensitivity might not exhibit NTC behavior. To support the aforementioned conclusions a chemical kinetic analysis of these three fuels is detailed in the next section.

\section{Chemical kinetic analysis}

A series of reaction pathways and sensitivity analyses was carried out to gain better understanding of the chemistry determining the reactivity of 2MF and the 2-MF/n-heptane blend. These analyses are essential in order to provide an insight into the interaction of $2-\mathrm{MF}$ and $n$-heptane, and to point out the areas where further work is needed to improve the predictability of the proposed mechanisms. The notations, complete names and molecular structures of the species used in this paper are presented in Table S2 of the Supplementary material. 


\subsection{Reaction path analysis}

A reaction path analysis highlighting the main consumption pathways of the stoichiometric $2-\mathrm{MF} / n$-heptane blend at a pressure of 20 bar, at two different temperatures of $690 \mathrm{~K}$ and $1175 \mathrm{~K}$, and at $30 \%$ 2-MF consumption is displayed in Fig. 13. It should be noted that for stoichiometric $2-\mathrm{MF} / n$ heptane/air mixture at a pressure of 20 bar, when $30 \%$ of 2-MF is consumed, the consumption of $n$-heptane is $23.69 \%, 34.71 \%$, and $42.03 \%$ at temperatures of $690 \mathrm{~K}, 800 \mathrm{~K}$, and $1175 \mathrm{~K}$, respectively. It can be seen in Fig. 13 that the consumption of $2-\mathrm{MF}$ is mainly on account of its reaction with the $\dot{\mathrm{OH}}$ radical. At a higher temperature of $1175 \mathrm{~K}, 39.6 \%$ of $2-\mathrm{MF}$ is consumed via $\mathrm{H}$-abstraction by $\dot{\mathrm{O}} \mathrm{H}$ and $16.3 \%$ is consumed by $\dot{\mathrm{O}} \mathrm{H}$ addition reactions along the double bonds. On the contrary, at a lower temperature of $690 \mathrm{~K}$,

$\dot{\mathrm{O} H}$ addition reactions dominate over $\mathrm{H}$-abstraction by $\dot{\mathrm{O}} \mathrm{H}$. While $81.0 \%$ of 2-MF is consumed by $\dot{\mathrm{O}} \mathrm{H}$ radical addition, the $\mathrm{H}$-abstraction reaction by $\dot{\mathrm{O}} \mathrm{H}$ consumes just $10.8 \%$ of $2-\mathrm{MF}$. H-abstraction predominately takes place at the methyl side chain because it has the lowest $\mathrm{C}-\mathrm{H}$ BDE (Fig. 3). The initial consumption pathways of $n$-heptane involve $\mathrm{H}$-abstraction by $\dot{\mathrm{O}} \mathrm{H}, \mathrm{HO}_{2}$, and $\dot{\mathrm{O}}$ radicals. The formed heptyl radicals are consumed predominantly via $\beta$-scission reactions at a higher temperature of $1175 \mathrm{~K}$ and via $\mathrm{O}_{2}$ addition to the heptyl radicals at a lower temperature of $690 \mathrm{~K}$. On the contrary, $\mathrm{F} 2 \dot{\mathrm{C}} \mathrm{H}_{2}$ is mainly consumed via its reaction with $\mathrm{HO}_{2}$ radical and does not undergo $\mathrm{O}_{2}$ addition reaction.

The main consumption pathways for heptyl radicals and $\mathrm{O}_{2}$ adducts 


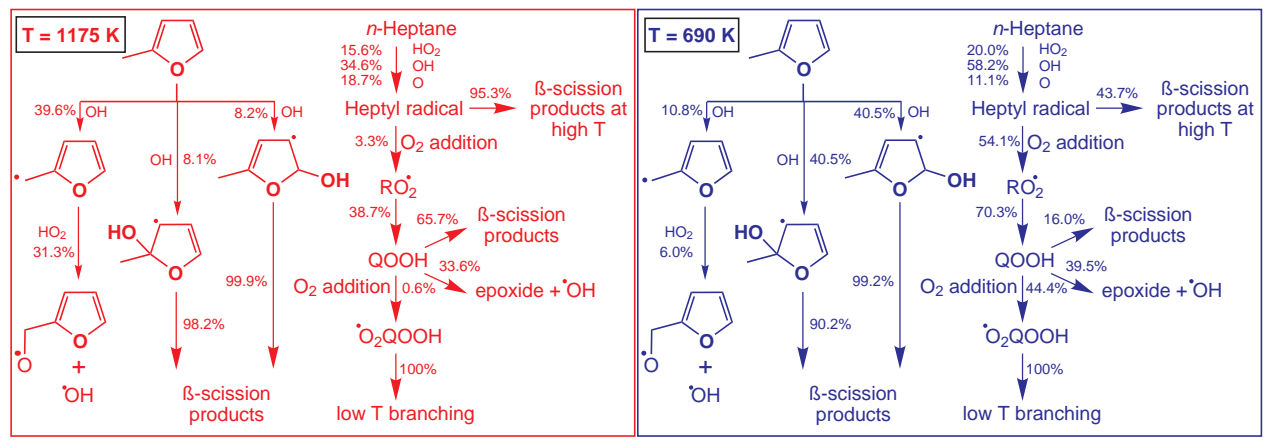

Figure 13: Simplified schematic of primary decomposition pathways of 2-MF and $n$ heptane in $2-\mathrm{MF} / n$-heptane/air mixtures at $30 \% 2$-MF consumption, at $\mathrm{P}=20$ bar, and at $\phi=1$ : (a) $\mathrm{T}=1175 \mathrm{~K}$ (red); (b) $\mathrm{T}=690 \mathrm{~K}$ (blue).

$\left(\mathrm{RO}_{2}\right)$ include the internal isomerization reactions at a lower temperature of $690 \mathrm{~K}$. The formed product $(\mathrm{QOOH})$ is either decomposed via second $\mathrm{O}_{2}$ addition reaction, which leads to low-temperature branching, or via cyclic ether formation or via $\beta$-scission reactions. At a higher temperature of $1175 \mathrm{~K}, \beta$-scission and epoxide formation are the main pathways, while at a lower temperature of $690 \mathrm{~K}$, low-temperature branching dominates. The addition of $\dot{\mathrm{OH}}$ radical to 2 -MF preferably takes place at $\alpha$-carbon sites. The addition of $\dot{\mathrm{O} H}$ radical at $\beta$-carbon sites does not appear in the reaction path analysis. Davis et al. [46] calculated the energy barriers of the addition of $\dot{\mathrm{OH}}$ radicals to $2-\mathrm{MF}$ at all of its four ring carbon sites. It was reported that the adducts formed at the $\beta$-carbon sites, MF23OH2J and MF24OH5J, are much less stable intermediates than the adducts formed at the $\alpha$-carbon sites, MF22OH3J and MF25OH4J. It was found in their study that both the adducts at $\alpha$-tertiary (MF22OH3J) and $\alpha$-secondary (MF25OH4J) sites have similar energies, and are thus produced in similar amounts (Fig. 13). 


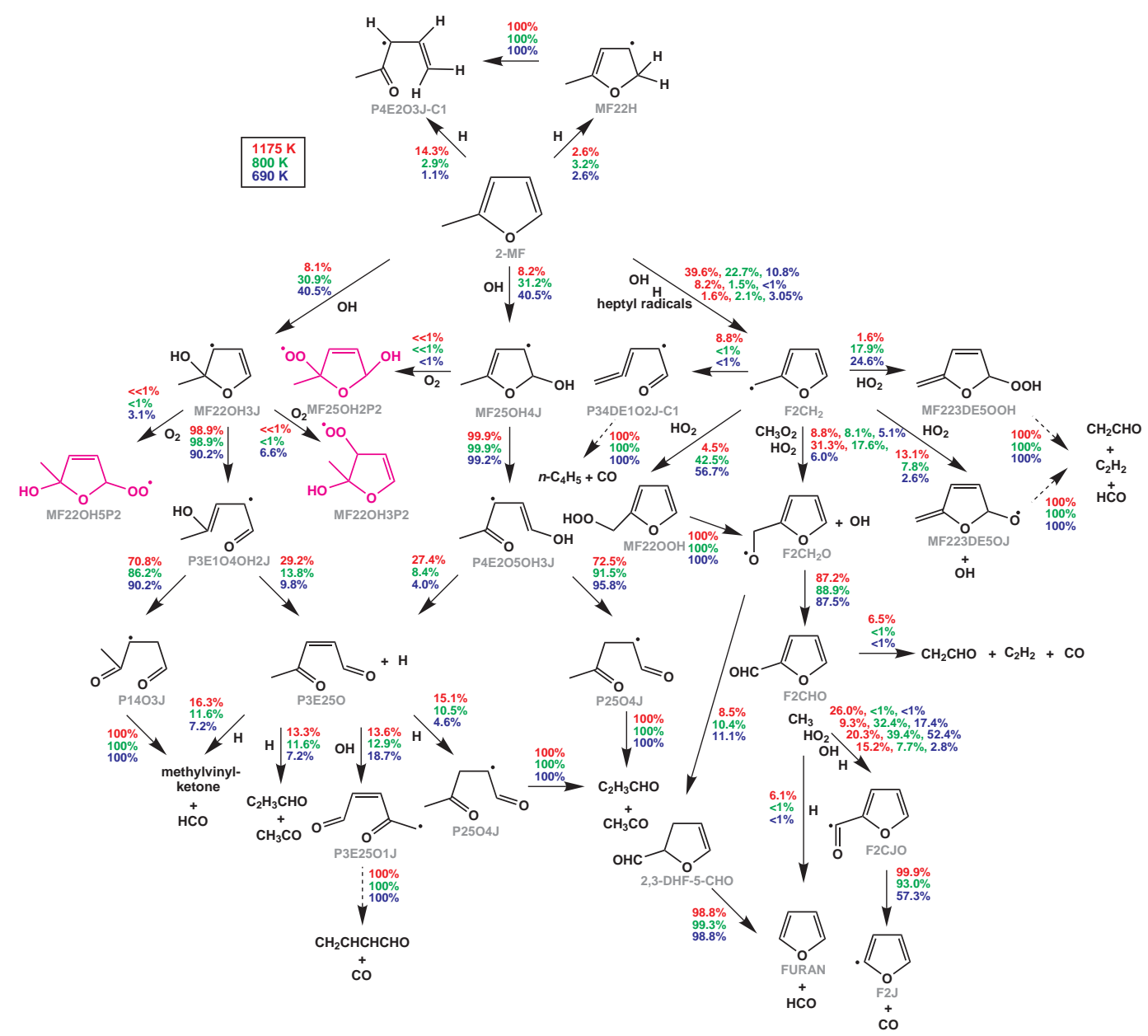

Figure 14: Simplified schematic of reaction path analysis of $2-\mathrm{MF}$ in the $2-\mathrm{MF} / n$ heptane/air mixtures at $30 \% 2$-MF consumption, at $\mathrm{P}=20 \mathrm{bar}$, and at $\phi=1: \mathrm{T}=$ $1175 \mathrm{~K}$ (red numbers); $\mathrm{T}=800 \mathrm{~K}$ (green numbers); $\mathrm{T}=690 \mathrm{~K}$ (blue numbers). Solid arrows correspond to the conversion in one step, while dashed arrows correspond to the conversion in more than one step.

The consumption pathways of $2-\mathrm{MF}$ in the mixture of $2-\mathrm{MF} / n$-heptane are presented in detail in Fig. 14. In order to elucidate the significant reaction pathways over the entire temperature range, reaction path analyses at three different temperatures of $1175 \mathrm{~K}, 800 \mathrm{~K}$, and $690 \mathrm{~K}$ are presented. In addition 


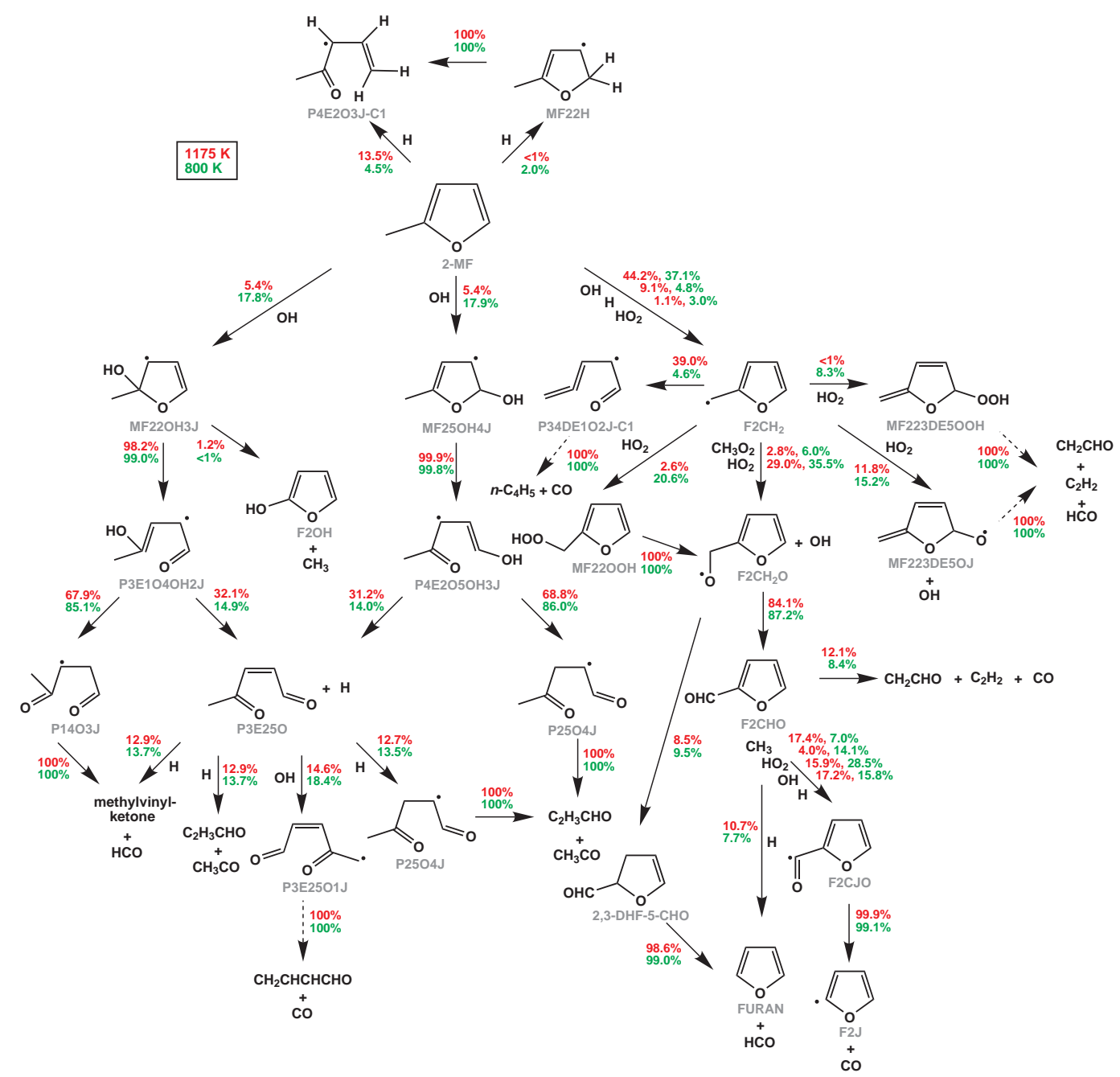

Figure 15: Simplified schematic of reaction path analysis of 2-MF in the 2-MF/air mixtures at $30 \% 2-\mathrm{MF}$ consumption, at $\mathrm{P}=20 \mathrm{bar}$, and $\phi=1: \mathrm{T}=1175 \mathrm{~K}$ (red numbers); $\mathrm{T}=$ $800 \mathrm{~K}$ (green numbers). Solid arrows correspond to the conversion in one step, while dashed arrows correspond to the conversion in more than one step.

to the reaction with $\dot{\mathrm{OH}}$ radical, a part of $2-\mathrm{MF}$ is also consumed via $\mathrm{H}-$ addition reaction and $\mathrm{H}$-abstraction by $\dot{\mathrm{H}}$ radicals and heptyl radicals. It can be seen in Fig. 14 that 2-MF consumption via H-abstraction by $\dot{H}$ radical and heptyl radicals is much less likely to occur in comparison to $\mathrm{H}$-abstraction by 
$\dot{\mathrm{OH}}$ radical. The reaction path analysis reveals that only a small amount of 2MF undergoes reaction with heptyl radicals, which is temperature dependent and is more likely to occur at lower temperatures. Therefore, it is expected that the main chemical interaction between 2-MF and $n$-heptane takes place through small radical species like $\dot{\mathrm{OH}}$ and $\mathrm{HO}_{2}$. For the reactions involving the addition of $\dot{\mathrm{H}}$ radical to $2-\mathrm{MF}$, it is observed that the formed adduct is very unstable and decomposes promptly to the $\beta$-scission product. The availability of higher energy at higher temperatures of $800 \mathrm{~K}$ and $1175 \mathrm{~K}$ allows for simultaneous $\mathrm{H}$-addition and $\beta$-scission reactions leading to direct ring opening, while bypassing the formation of the unstable adduct. On the contrary, at a lower temperature of $690 \mathrm{~K}, \mathrm{H}$-addition along the double bond is more likely to occur in comparison to the direct $\beta$-scission reaction because of the higher energy is required to achieve ring opening.

2-MF/ÖH adducts formed at the $\alpha$ sites of 2-MF, namely MF22OH3J and MF25OH4J, decompose preferentially via $\beta$-scission reactions. Although the pathways including the addition of $\mathrm{O}_{2}$ to these adducts are not seen to play a big role at higher temperatures, at a lower temperature of $690 \mathrm{~K}, 9.7 \%$ of the total 2-MF/ÖH adducts undergo $\mathrm{O}_{2}$ addition reactions. Since these pathways are not the main consumption pathways of MF22OH3J and MF25OH4J, further consumption of the formed products has not been included here for the sake of brevity and has been presented in Fig. S12 of the Supplementary material. It can be seen in Fig. S12 that the formed products in these reactions undergo alkene-specific Waddington pathways, which ultimately leads to the 
formation of carbonyls and $\dot{\mathrm{O}} \mathrm{H} / \mathrm{HO}_{2}$ radicals. The $\beta$-scission of MF22OH3J and MF25OH4J takes place predominantly at the $\mathrm{C}-\mathrm{O}$ sites because this poses a much lower energy barrier in comparison to that of the $\mathrm{C}-\mathrm{C}$ bond scission [90]. The formed products ultimately decompose in several steps into stable methylvinyl-ketone, carbon monoxide, acetyl radicals, and some formyl species. Under the studied conditions, $\mathrm{F} 2 \dot{\mathrm{C}} \mathrm{H}_{2}$ is primarily consumed by its reaction with $\mathrm{HO}_{2}\left(89.9 \%\right.$ at $690 \mathrm{~K}$ ), forming $\mathrm{F}_{2} \mathrm{CH}_{2} \dot{\mathrm{O}}$ (2-furylmethanoxy radical), MF22OOH, MF223DE5OJ, and MF223DE5OOH. The significance of the reaction of $\mathrm{F} 2 \dot{\mathrm{C}} \mathrm{H}_{2}$ with $\mathrm{H}_{2}$, which leads to the formation of $\mathrm{F}_{2} \mathrm{CH}_{2} \dot{\mathrm{O}}$ and MF223DE5OJ, increases with an increase in the temperature. On the contrary, the relevance of $\mathrm{F} 2 \dot{\mathrm{C}} \mathrm{H}_{2}$ with $\mathrm{HO}_{2}$ reactions leading to the formation of MF22OOH and MF223DE5OOH decreases with an increase in the temperature.

The reaction of $\mathrm{F} 2 \dot{\mathrm{C}} \mathrm{H}_{2}$ with $\mathrm{CH}_{3} \dot{\mathrm{O}}_{2}$ forming $\mathrm{F} 2 \mathrm{CH}_{2} \mathrm{O}$ and $\mathrm{CH}_{3} \dot{\mathrm{O}}$ is also a contributor to $\mathrm{F} 2 \dot{\mathrm{C}} \mathrm{H}_{2}$ consumption. The significance of this reaction increases with a decrease in the temperature. The thermal decomposition pathways of $\mathrm{F} 2 \dot{\mathrm{C}} \mathrm{H}_{2}$ becomes important at higher temperatures of $800 \mathrm{~K}$ and $1175 \mathrm{~K}$. The branching ratio between the bimolecular recombination reaction of $\mathrm{F} 2 \dot{\mathrm{C}} \mathrm{H}_{2}$ with $\mathrm{HO}_{2}$ and the thermal decomposition reaction is important, as the former tends to increase reactivity due to the formation of a reactive $\dot{\mathrm{O}} \mathrm{H}$ radical, while the latter resulting into chain termination. $\mathrm{MF} 22 \mathrm{OOH}$, a product of the bimolecular reaction of $\mathrm{F} 2 \dot{\mathrm{C}} \mathrm{H}_{2}$ with $\mathrm{HO}_{2}$, readily undergoes the formation of $\mathrm{F}_{2} \mathrm{CH}_{2} \mathrm{O}$. Two out of the rest of the three products, MF223DE5OJ 
and MF223DE5OOH, decompose into vinyloxy radical ( $\left.\dot{\mathrm{C}} \mathrm{H}_{2} \mathrm{CHO}\right)$, acetylene, and formyl radical. The major product of the reaction of $\mathrm{F} 2 \dot{\mathrm{C}} \mathrm{H}_{2}$ with $\mathrm{HO}_{2}, \mathrm{~F}_{2} \mathrm{CH}_{2} \dot{\mathrm{O}}$, is an unstable intermediate and is mostly converted into stable 2-formylfuran (F2CHO) at all the three temperatures. F2CHO ultimately decomposes to furan, furfuryl radical, and formyl radical. Therefore, a range of stable furanics has been seen to be important products of 2-MF oxidation, at all the studied conditions. Although the present model includes further pathways of these products, these pathways are not the subject of detailed analyses and are excluded from the discussion here.

In order to compare the reaction pathways of the $2-\mathrm{MF} / n$-heptane blend with those of pure 2-MF, reaction path analyses for the stoichiometric 2$\mathrm{MF} / \mathrm{O}_{2} / \mathrm{N}_{2}$ mixtures were also performed. These analyses were performed at the time when $30 \%$ of the initial fuel concentration is already consumed. Figure 15 shows the reaction path analyses of pure 2-MF at the same conditions as those used for the $2-\mathrm{MF} / n$-heptane blend, i.e. a pressure of 20 bar and temperatures of $800 \mathrm{~K}$ and $1175 \mathrm{~K}$. As observed in the mixture of $2-\mathrm{MF} / n$ heptane, pure 2-MF is also preliminarily consumed by $\mathrm{H}$-abstraction by $\dot{\mathrm{OH}}$ and $\dot{\mathrm{O} H}$ addition reactions. One of the most significant differences in the consumption of $2-\mathrm{MF}$ in the $2-\mathrm{MF} / n$-heptane $/ \mathrm{O}_{2} / \mathrm{N}_{2}$ and in $2-\mathrm{MF} / \mathrm{O}_{2} / \mathrm{N}_{2}$ mixtures is in the different dominance of the H-abstraction and the $\dot{\mathrm{O}} \mathrm{H}$ addition reaction pathways. At a temperature of $800 \mathrm{~K}$, while 2-MF in 2$\mathrm{MF} / n$-heptane $/ \mathrm{O}_{2} / \mathrm{N}_{2}$ mixture is consumed $22.7 \%$ via $\mathrm{H}$-abstraction by $\dot{\mathrm{OH}}$ and $62.1 \%$ of it via $\dot{\mathrm{OH}}$ addition reactions, $2-\mathrm{MF}$ in $2-\mathrm{MF} / \mathrm{O}_{2} / \mathrm{N}_{2}$ mixture 
is consumed $37.1 \%$ via $\mathrm{H}$-abstraction by $\dot{\mathrm{OH}}$ and only $35.7 \%$ of it via $\dot{\mathrm{O}} \mathrm{H}$ addition to the ring. The same feature of relatively higher addition of $\dot{\mathrm{O} H}$ to the ring in the $2-\mathrm{MF} / n$-heptane blend in comparison to that in pure $2-\mathrm{MF}$ is also observed at $1175 \mathrm{~K}$. This is because of the presence of $n$-heptane in the mixture, which provides $\dot{\mathrm{O} H}$ radical pools and increases the reactivity of 2-MF. Therefore, the amount of consumption of 2-MF via a particular pathway differs in pure $2-\mathrm{MF}$ from that in the $2-\mathrm{MF} / n$-heptane blend. It should be noted that for the sake of brevity, not all pathways of 2-MF consumption are shown in Fig. 15. The rest of the 2-MF in 2-MF/air mixture is consumed via $\mathrm{H}$-abstraction by $\dot{\mathrm{O}}$ and $\mathrm{H}$-addition reactions at different carbon sites of 2-MF. Also, a similar set of reactions are responsible for the rest of the $2-\mathrm{MF}$ consumption in the $2-\mathrm{MF} / n$-heptane/air mixture. Further, the formed adducts, MF22OH3J and MF25OH4J, decompose in a similar fashion in both pure 2-MF and the $2-\mathrm{MF} / n$-heptane blend.

The sole difference in the consumption of MF22OH3J is in the formation of $1.2 \%$ stable 2 -furanol specie in pure 2 -MF at a temperature of $1175 \mathrm{~K}$ (Fig. 14), which was not observed in the blend. Similar to that in the blend, the decomposition of $\mathrm{F} 2 \dot{\mathrm{C}} \mathrm{H}_{2}$ fuel radical takes place preferentially by its reaction with $\mathrm{HO}_{2}$ to produce $\mathrm{F}_{2} \mathrm{CH}_{2} \dot{\mathrm{O}}$. As the temperature is lowered to $800 \mathrm{~K}$, the reaction of $\mathrm{F} 2 \dot{\mathrm{C}} \mathrm{H}_{2}$ with $\mathrm{CH}_{3} \dot{\mathrm{O}}_{2}$ also starts to play a role in its consumption, with $6 \%$ of $\mathrm{F} 2 \dot{\mathrm{C}} \mathrm{H}_{2}$ consumed via this reaction. One difference in the consumption of $\mathrm{F} 2 \dot{\mathrm{C}} \mathrm{H}_{2}$ is that in pure 2-MF, the thermal decomposition pathway leading to the formation of the ring opened product is more 
prominent in comparison to that in the blend. In pure $2-\mathrm{MF}, 39.5 \%$ and $4.6 \%$ of $\mathrm{F} 2 \dot{\mathrm{C}} \mathrm{H}_{2}$ undergoes thermal decomposition at temperatures of $1175 \mathrm{~K}$ and $800 \mathrm{~K}$, respectively, whereas, in the blend, $8.8 \%$ and $<1 \%$ of $\mathrm{F} 2 \dot{\mathrm{C}} \mathrm{H}_{2}$ converts into the ring opened products at temperatures of $1175 \mathrm{~K}$ and $800 \mathrm{~K}$, respectively.

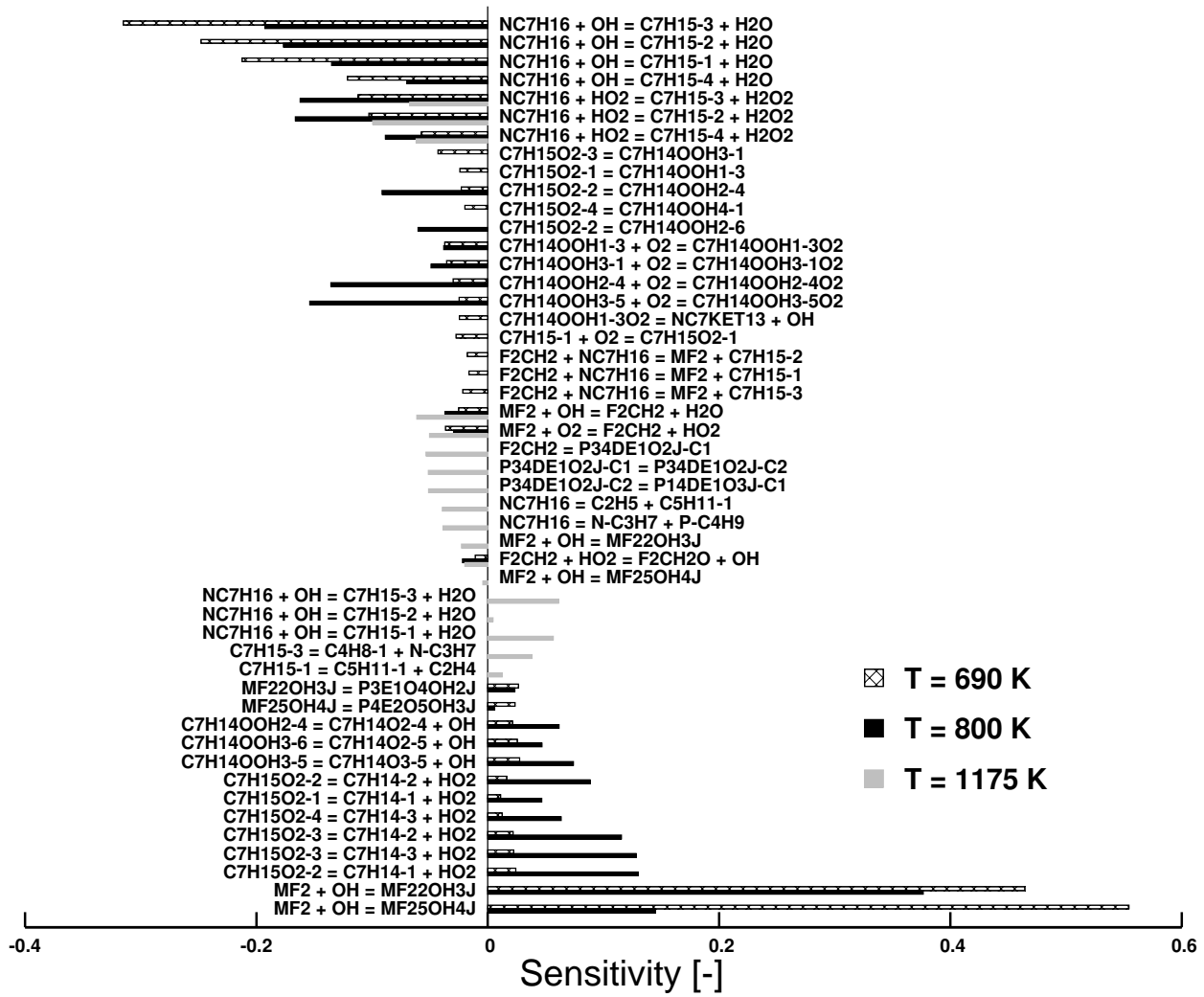

Figure 16: Sensitivity coefficient of main 2-MF and $n$-heptane specific reactions showing the effect of temperature at $650 \mathrm{~K}, 800 \mathrm{~K}$, and $1175 \mathrm{~K}$ on $2-\mathrm{MF} / n$-heptane ignition delay time, $\mathrm{P}=20$ bar and $\phi=1$. 


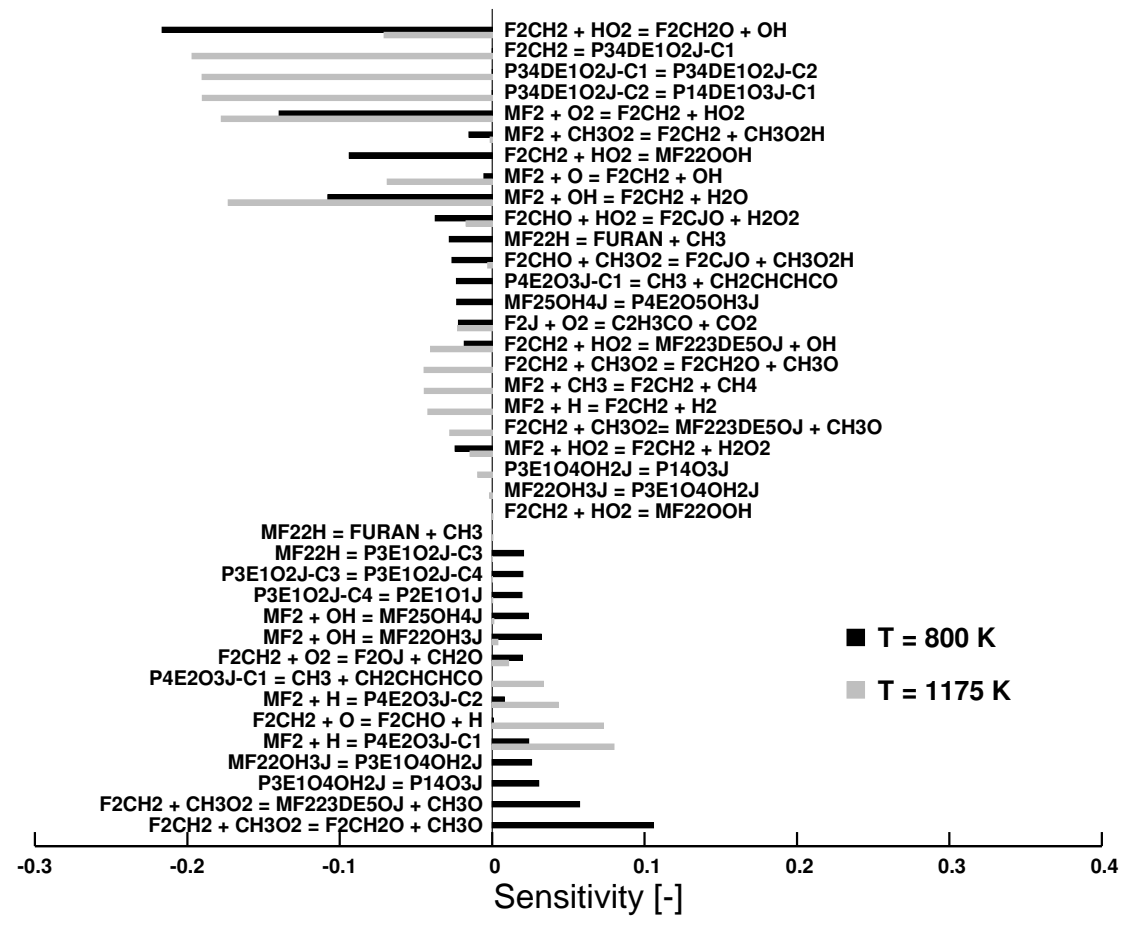

Figure 17: Sensitivity coefficient of main 2-MF specific reactions showing the effect of temperature at $800 \mathrm{~K}$ and $1175 \mathrm{~K}$ on $2-\mathrm{MF}$ ignition delay time, $\mathrm{P}=20$ bar and $\phi=1$.

\subsection{Sensitivity analysis}

To better understand the kinetics controlling the oxidation of 2-MF, brute force sensitivity analyses for 2-MF/n-heptane/air and 2-MF/air mixtures were performed at the same conditions as for the reaction path analyses. The sensitivity coefficient, $s$, of a reaction for its effect on the ignition delay time is determined by multiplying its rate constant by a factor of two and evaluating the relative change in altered ignition delays due to this rate change. Detailed explanations and definition for $s$ can be found in previous studies [64, 91]. A positive value of $s$ implies that the reaction has an inhibiting effect on the 
overall reactivity and results in longer ignition delays and vice versa.

The results for the sensitivity analysis for $2-\mathrm{MF} / n$-heptane are shown in Fig. 16. For the sake of brevity, only the reactions specific to 2-MF and $n$-heptane oxidation were taken into consideration, and those related to the oxidation of smaller species were left out from the analyses. It can be seen in Fig. 16 that $\mathrm{H}$-abstraction reactions from $n$-heptane have the most negative $s$ value for the $2-\mathrm{MF} / n$-heptane blend. The $\mathrm{H}$-abstraction reactions by $\dot{\mathrm{O}} \mathrm{H}$ radicals have a negative $s$ value and promote the reactivity of the blend at temperatures of $690 \mathrm{~K}$ and $800 \mathrm{~K}$. However, at a higher temperature of $1175 \mathrm{~K}$ these reactions are found to have a positive $s$ value because of their limited participation in degenerate branching due to competition with the $\mathrm{H}$-abstraction reactions by $\mathrm{HO}_{2}$ radicals. Reactions including isomerization of $\mathrm{RO}_{2}$ to $\mathrm{QOOH}$ and addition of $\mathrm{O}_{2}$ to $\mathrm{QOOH}$ for $n$-heptane were found to have a negative $s$ value at temperatures of $690 \mathrm{~K}$ and $800 \mathrm{~K}$, whereas, at a temperature of $1175 \mathrm{~K}$, these reactions do not appear in the sensitivity plot. These results are consistent with the fact that at low temperatures the isomerization of $\mathrm{RO}_{2}$ to $\mathrm{QOOH}$ and the addition of $\mathrm{O}_{2}$ to $\mathrm{QOOH}$ are the rate limiting steps in low-temperature degenerate branching. On the contrary, at a higher temperature of $1175 \mathrm{~K}$ decomposition of $\mathrm{H}_{2} \mathrm{O}_{2}$ becomes important because of the high amount of energy available at this temperature. The reaction steps describing cyclic ether formation and concerted elimination compete with low-temperature degenerate branching pathways of $n$-heptane and thus have a positive $s$ value. 
With regards to the reactions related to $2-\mathrm{MF}$, $\dot{\mathrm{OH}}$ radical addition is found to be the most sensitive. These reactions have a positive $s$ value at $690 \mathrm{~K}$ and $800 \mathrm{~K}$, whereas, at a higher temperature of $1175 \mathrm{~K}$, these $\dot{\mathrm{O}} \mathrm{H}$ addition reactions to the furan ring have a negligible negative $s$ value. It can be seen in Fig. 16 that $\mathrm{H}$-abstraction by $\dot{\mathrm{O}} \mathrm{H}$ radical from the methyl side chain of 2-MF has a negative $s$ value at all three temperatures, and its magnitude decreases with a decrease in temperature. This behavior is expected because these reactions act as $\dot{\mathrm{O}} \mathrm{H}$ radical sinks and are competitive with the primary oxidation pathway of $n$-heptane $(n$-heptane $+\dot{\mathrm{OH}})$. As observed in the oxidation of other stable aromatic hydrocarbon species and furanics like toluene [70], propylbenzene [92], and 2,5-DMF [66], the reaction of $\mathrm{O}_{2}$ at the methyl side chain of $2-\mathrm{MF}$ has a negative $s$ value. Independent of the temperature, reaction of the predominantly formed fuel radical $\mathrm{F} 2 \dot{\mathrm{C}} \mathrm{H}_{2}$ with $\mathrm{HO}_{2}$ radical has a negative $s$ value, which contributes to the increased reactivity of $2-\mathrm{MF}$ due to the formation of a reactive $\mathrm{OH}$ radical in this reaction step.

Upon inclusion of the direct co-oxidation reactions between 2-MF and heptyl radicals in the chemical kinetic mechanism, a small amount of 2-MF decomposition at $690 \mathrm{~K}$ was observed in the reaction path analysis. However, these co-oxidation reactions are ineffective and do not appear in the sensitivity analyses as seen in Fig. 16. The only significant interaction that takes place between these two fuels is via smaller radicals, which is limited to lower temperatures. 
Figure 17 shows the sensitivity analysis for 2-MF in a stoichiometric 2$\mathrm{MF} /$ air mixture, with the same conditions as in the reaction path analyses of this mixture. Only the reactions specific to $2-\mathrm{MF}$ oxidation were taken into consideration, and those related to the oxidation of smaller species were left out from the analyses. Similar to what was observed in the oxidation of the 2$\mathrm{MF} / n$-heptane blend, $\mathrm{F} 2 \dot{\mathrm{C}} \mathrm{H}_{2}+\mathrm{HO}_{2}$ reaction has a negative $s$ value whose magnitude is much higher in comparison to that in the $2-\mathrm{MF} / n$-heptane blend. This bimolecular reaction of $\mathrm{HO}_{2}$ with primary fuel radical $\mathrm{F}_{2} \dot{\mathrm{C}} \mathrm{H}_{2}$ to produce $\mathrm{F} 2 \mathrm{CH}_{2} \mathrm{O}$ and $\dot{\mathrm{O}} \mathrm{H}$ radical is found to be the most promoting reaction in the oxidation of pure 2-MF. Therefore, it has a significant control over the predicted ignition delay times under the studied conditions. Additionally, $2-\mathrm{MF}+\dot{\mathrm{OH}}$ reactions also play a major role in the oxidation of pure $2-\mathrm{MF}$ and are found to be temperature dependent. H-abstraction by $\dot{\mathrm{O}} \mathrm{H}$ on the methyl side chain of 2-MF has a negative $s$ value for both the temperatures of $800 \mathrm{~K}$ and $1175 \mathrm{~K}$, while $\dot{\mathrm{OH}}$ radical addition reactions to 2-MF inhibit its ignition. H-abstraction by $\dot{\mathrm{O}} \mathrm{H}$ has a more negative $s$ value at $1175 \mathrm{~K}$ than at $800 \mathrm{~K}$. The $s$ value of $\dot{\mathrm{OH}}$ radical addition was found to become more positive with decreasing temperature.

Like in the $2-\mathrm{MF} / n$-heptane blend, H-abstraction reaction of 2 -MF by $\mathrm{O}_{2}$ is found to promote its ignition. At a higher temperature of $1175 \mathrm{~K}$, H-abstraction reactions by $\mathrm{HO}_{2}, \dot{\mathrm{C}} \mathrm{H}_{3}$, and $\dot{\mathrm{O}}$ are also found to play a role in promoting 2-MF ignition. On the contrary, $\mathrm{H}$-abstraction by $\mathrm{CH}_{3} \dot{\mathrm{O}}_{2}$ is observed to be influential only at an intermediate temperature of $800 \mathrm{~K}$. 
Consequently, all the $\mathrm{H}$-abstraction reactions from 2-MF are found to promote its ignition, which take place predominantly at its methyl side chain. It is clear from sensitivity analyses of the $2-\mathrm{MF} / n$-heptane blend and pure 2-MF that the same specific set of 2-MF reactions exert an influence on the overall chemical kinetic mechanism. However, the degree of sensitivity of these reactions varies significantly between the pure and the blended fuels.

\section{Conclusions}

In the present work, a comprehensive experimental and modeling study of the oxidation of a lignocellulosic biofuel 2-MF and its blend with $n$-heptane has been reported. A detailed mechanism that describes the low- to hightemperature oxidation behavior of 2-MF/n-heptane blends has been developed. A number of recent advancements in the understanding of the oxidation of 2-MF was compiled and included in the proposed model. The ignition delay times of pure 2-MF and 2-MF blended with $n$-heptane (50/50 molar \%) were obtained in two different kinds of experimental setups, an ST and an RCM. The measurements were performed spanning a wide range of temperatures, pressures, and equivalence ratios. The experimental data obtained from the setups provide a reasonable validation metric for the developed chemical kinetic model. Subsequently, the developed model was validated against the measurements made within this work as well as against several other datasets available in the existing literature. The qualitative and quantitative trends of ignition delay times, laminar burning velocities, and flame 
species histories are found to be reasonably predicted by the proposed model. 11

An NTC behavior, which is typical of $n$-alkanes, was observed during the ignition of the $2-\mathrm{MF} / n$-heptane blend, whereas, in case of pure $2-\mathrm{MF}$, a typical temperature dependent Arrhenius behavior was observed. A clear trend showing a reduction in the ignition delay time with an increase in pressure and fuel concentration was observed for both pure 2-MF and the $2-\mathrm{MF} / n$ heptane blend. The ignition behaviors of pure 2-MF, the 2-MF/n-heptane blend, and pure $n$-heptane were compared, and it was found that the addition of $n$-heptane to $2-\mathrm{MF}$ leads to a decrease in the ignition delay time for the blend. The reaction path and sensitivity analyses at various conditions of interest were carried out in order to find important reaction pathways in the oxidation of $2-\mathrm{MF}$ and $2-\mathrm{MF} / n$-heptane blends. Particularly, the ignition of $2-\mathrm{MF}$ and $2-\mathrm{MF} / n$-heptane blends was found to be driven by $\mathrm{H}$-abstraction by $\dot{\mathrm{OH}}$ and by $\dot{\mathrm{O}} \mathrm{H}$ addition reactions. Reactions specific to low-temperature oxidation of alkene, such as Waddington elimination and Waddington concerted elimination, were seen to play a significant role for the prediction of ignition delay times below $685 \mathrm{~K}$. For the $2-\mathrm{MF} / n$-heptane blend, co-oxidation reactions have little effect on the ignition delay times, and the effect is limited to the lower temperature regime. We propose that the main interaction between 2-MF and $n$-heptane involves smaller radicals, especially $\dot{\mathrm{O}} \mathrm{H}$. It is observed that different reaction pathways exert different degrees of influence in deciding the overall oxidation behavior of pure 2-MF 
and the $2-\mathrm{MF} / n$-heptane blend. The oxidation of pure $2-\mathrm{MF}$ is mainly controlled by its $\mathrm{H}$-abstraction by $\dot{\mathrm{O}} \mathrm{H}$, whereas, the $\dot{\mathrm{O}} \mathrm{H}$ addition to $2-\mathrm{MF}$ is the main rate limiting step in the oxidation of the $2-\mathrm{MF} / n$-heptane blend. The present work provides an insight into how the presence of $n$-heptane affects the ignition of 2-MF, thus providing a basis for understanding the oxidation behavior of higher chain furanics blended with reactive conventional fuel components. Further refinements in the model would improve its performance. Of particular interest would be the theoretical and experimental calculation of the rate parameters of the addition reaction of $\dot{\mathrm{OH}}$ with 2-MF. These reactions show particular sensitivity at low temperatures. In order to further improve the understanding of low-temperature oxidation of 2-MF and its interaction with conventional fuel components, low-temperature species profiles data of 2-MF blended with highly reactive hydrocarbon fuels will be useful.

\section{Acknowledgments}

This work was performed as part of the Cluster of Excellence TailorMade fuels from Biomass, which is funded by the Excellence Initiative by the German federal and state governments to promote science and research at German universities. The work performed by the Clean Combustion Research Center was supported by competitive research funding from King Abdullah University of Science and Technology (KAUST). The authors would

like to thank Dr. Christian Hemken (PCFC, RWTH Aachen University) for 
performing the flow reactor simulations.

\section{References}

[1] C.K. Westbrook, W.J. Pitz, H.J. Curran, Chemical kinetic modeling study of the effects of oxygenated hydrocarbons on soot emissions from diesel engines, J. Phys. Chem. A 110 (2006) 6912-6922.

[2] G. Najafi, B. Ghobadian, T. Tavakoli, D.R. Buttsworth, T.F. Yusaf, M. Faizollahnejad, Performance and exhaust emissions of a gasoline engine with ethanol blended gasoline fuels using artificial neural network, Appl. Energy 86 (2009) 630-639.

[3] M. Al-Hasan, Effect of ethanol-unleaded gasoline blends on engine performance and exhaust emission, Energy Conver. Manage. 44 (2003) 1547-1561.

[4] A.K. Agarwal, Biofuels (alcohols and biodiesel) applications as fuels for internal combustion engines, Prog. Energy Combust. Sci. 33 (2007) 233271.

[5] B.Q. He, S.J. Shuai, J.X. Wang, H. He, The effect of ethanol blended diesel fuels on emissions from a diesel engine, Atmos. Environ. 37 (2003) 4965-4971.

[6] X. Shi, X. Pang, Y. Mu, H. He, S. Shuai, J. Wang, H. Chen, R. Li, 
Emission reduction potential of using ethanol-biodiesel-diesel fuel blend on a heavy-duty diesel engine, Atmos. Environ. 40 (2006) 2567-2574.

[7] S.M. Sarathy, P. Oßwald, N. Hansen, K. Kohse-Höinghaus, Alcohol combustion chemistry, Prog. Energy Combust. Sci. 44 (2014) 40-102.

[8] R. Magnusson, C. Nilsson, B. Andersson, Emissions of aldehydes and ketones from a two-stroke engine using ethanol and ethanol-blended gasoline as fuel, Environ. Sci. Technol. 36 (2002) 1656-1664.

[9] N.D. Brinkman, SAE Technical Paper 1981-02-01 (1981).

[10] E. Christensen, J. Yanowitz, M. Ratcliff, R.L. McCormick, Renewable oxygenate blending effects on gasoline properties, Energy Fuels 25 (2011) 4723-4733.

[11] M. Thewes, M. Muether, S. Pischinger, M. Budde, A. Brunn, A. Sehr, P. Adomeit, J. Klankermayer, Analysis of the impact of 2-methylfuran on mixture formation and combustion in a direct-injection spark-ignition engine, Energy Fuels 25 (2011) 5549-5561.

[12] A. Sudholt, L. Cai, J. Heyne, F.M. Haas, H. Pitsch, F.L. Dryer, Ignition characteristics of a bio-derived class of saturated and unsaturated furans for engine applications, Proc. Combust. Inst. 35 (2015) 2957-2965.

[13] C. Wang, H. Xu, R. Daniel, A. Ghafourian, J.M. Herreros, S. Shuai, X. Ma, Combustion characteristics and emissions of 2-methylfuran com- 
pared to 2, 5-dimethylfuran, gasoline and ethanol in a DISI engine, Fuel 103 (2013) 200-211.

[14] S. Gouli, E. Lois, S. Stournas, Effects of some oxygenated substitutes on gasoline properties, spark ignition engine performance, and emissions, Energy Fuels 12 (1998) 918-924.

[15] H. Wei, D. Feng, G. Shu, M. Pan, Y. Guo, D. Gao, W. Li, Experimental investigation on the combustion and emissions characteristics of 2-methylfuran gasoline blend fuel in spark-ignition engine, Appl. Energy 132 (2014) 317-324.

[16] M. Mascal, E.B. Nikitin, Direct, high-yield conversion of cellulose into biofuel, Angew. Chem. Int. Ed. 120 (2008) 8042-8044.

[17] K.P. Somers, J.M. Simmie, F. Gillespie, U. Burke, J. Connolly, W.K. Metcalfe, F. Battin-Leclerc, P. Dirrenberger, O. Herbinet, P.A. Glaude, H.J. Curran, A high temperature and atmospheric pressure experimental and detailed chemical kinetic modelling study of 2-methylfuran oxidation, Proc. Combust. Inst. 34 (2013) 225-232.

[18] L. Wei, C. Tang, X. Man, Z. Huang, Shock-tube experiments and kinetic modeling of 2-methylfuran ignition at elevated pressure, Energy Fuels 27 (2013) 7809-7816.

[19] Y. Uygun, S. Ishihara, H. Olivier, A high pressure ignition delay time 
study of 2-methylfuran and tetrahydrofuran in shock tubes, Combust. Flame 161 (2014) 2519-2530.

[20] M.A. Eldeeb, B. Akih-Kumgeh, Reactivity trends in furan and alkyl furan combustion, Energy Fuels 28 (2014) 6618-6626.

[21] N. Xu, C. Tang, X. Meng, X. Fan, Z. Tian, Z. Huang, Experimental and kinetic study on the ignition delay times of 2,5-dimethylfuran and the comparison with 2-methylfuran and furan, Energy Fuels 29 (2015) $5372-5381$.

[22] A. Sudholt, C. Lee, J. Klankermayer, R.X. Fernandes, H. Pitsch, Ignition characteristics of saturated and unsaturated furans, Combust. Flame 171 (2016) 133-136.

[23] N. Xu, Y. Wu, C. Tang, P. Zhang, X. He, Z. Wang, Z. Huang, Experimental study of 2,5-dimethylfuran and 2-methylfuran in a rapid compression machine: comparison of the ignition delay times and reactivity at low to intermediate temperature, Combust. Flame 168 (2016) 216227.

[24] L.S. Tran, C. Togbé, D. Liu, D. Felsmann, P. Oßwald, P.A. Glaude, R. Fournet, B. Sirjean, F. Battin-Leclerc, K. Kohse-Höinghaus, Combustion chemistry and flame structure of furan group biofuels using molecular-beam mass spectrometry and gas chromatography - Part II: 2-methylfuran, Combust. Flame 161 (2014) 766-779. 
[25] X. Ma, C. Jiang, H. Xu, S. Shuai, H. Ding, Laminar burning characteristics of 2-methylfuran compared with 2, 5-dimethylfuran and isooctane, Energy Fuels 27 (2013) 6212-6221.

[26] X. Ma, C. Jiang, H. Xu, H. Ding, S. Shuai, Laminar burning characteristics of 2-methylfuran and isooctane blend fuels, Fuel 116 (2014) 281-291.

[27] Z. Cheng, Q. Niu, Z. Wang, H. Jin, G. Chen, M. Yao, L. Wei, Experimental and kinetic modeling studies of low-pressure premixed laminar 2-methylfuran flames, Proc. Combust. Inst. 36 (2017) 1295-1302.

[28] M.A. Grela, V.T. Amorebieta, A.J. Colussi, Very low pressure pyrolysis of furan, 2-methylfuran and 2, 5-dimethylfuran. The stability of the furan ring, J. Phys. Chem. 89 (1985) 38-41.

[29] A. Lifshitz, M. Bidani, S. Bidani, Thermal reactions of cyclic ethers at high temperatures. III. Pyrolysis of furan behind reflected shocks, J. Phys. Chem. 90 (1986) 5373-5377.

[30] A. Lifshitz, C. Tamburu, R. Shashua, Decomposition of 2-methylfuran. Experimental and modeling study, J. Phys. Chem. A 101 (1997) 10181029.

[31] A. Lifshitz, C. Tamburu, R. Shashua, Thermal decomposition of 2, 5dimethylfuran. Experimental results and computer modeling, J. Phys. Chem. A 102 (1998) 10655-10670. 
[32] R. Liu, X. Zhou, L. Zhai, Theoretical investigation of unimolecular decomposition channels of furan4, J. Comput. Chem. 19 (1998) 240-249.

[33] R. Liu, X. Zhou, T. Zuo, The pyrolysis mechanism of furan revisited, Chem. Phys. Lett. 325 (2000) 457-464.

[34] K. Sendt, G.B. Bacskay, J.C. Mackie, Pyrolysis of furan: ab initio quantum chemical and kinetic modeling studies, J. Phys. Chem. A 104 (2000) $1861-1875$.

[35] J.M. Simmie, H.J. Curran, J. Phys. Chem. A 113 (2009) 5128-5137.

[36] J.M. Simmie, W.K. Metcalfe, Ab initio study of the decomposition of 2,5-dimethylfuran, J. Phys. Chem. A 115 (2011) 8877-8888.

[37] K.P. Somers, J.M. Simmie, W.K. Metcalfe, H.J. Curran, The pyrolysis of 2-methylfuran: A quantum chemical, statistical rate theory and kinetic modelling study, Phys. Chem. Chem. Phys. 16 (2014) 5349-5367.

[38] X. Wu, Z. Huang, C. Jin, X. Wang, L. Wei, Laminar burning velocities and Markstein lengths of 2,5-dimethylfuran-air premixed flames at elevated temperatures, Combust. Sci. Technol. 183 (2010) 220-237.

[39] X. Wu, Z. Huang, X. Wang, C. Jin, C. Tang, L. Wei, C.K. Law, Laminar burning velocities and flame instabilities of 2, 5-dimethylfuran-air mixtures at elevated pressures, Combust. Flame 158 (2011) 539-546. 
[40] X. Wu, Z. Huang, C. Jin, X. Wang, B. Zheng, Y. Zhang, L. Wei, Measurements of laminar burning velocities and Markstein lengths of 2, 5dimethylfuran- air- diluent premixed flames, Energy Fuels 23 (2009) $4355-4362$.

[41] X. Wu, Z. Huang, T. Yuan, K. Zhang, L. Wei, Identification of combustion intermediates in a low-pressure premixed laminar 2, 5dimethylfuran/oxygen/argon flame with tunable synchrotron photoionization, Combust. Flame 156 (2009) 1365-1376.

[42] N. Xu, Y. Wu, C. Tang, P. Zhang, X. He, Z. Wang, Z. Huang, Ignition delay times of low alkylfurans at high pressures using a rapid compression machine, Proc. Combust. Inst. 36 (2017) 323-332.

[43] L. Wei, C. Tang, X. Man, X. Jiang, Z. Huang, High-temperature ignition delay times and kinetic study of furan, Energy Fuels 26 (2012) 20752081.

[44] K. Alexandrino, Á. Millera, R. Bilbao, M.U. Alzueta, 2-Methylfuran oxidation in the absence and presence of NO, Flow Turb. Combust. 96 (2016) 343-362.

[45] L.S. Tran, Z. Wang, H.H. Carstensen, C. Hemken, F. Battin-Leclerc, K. Kohse-Höinghaus, Comparative experimental and modeling study of the low-to moderate-temperature oxidation chemistry of 2,5-dimethylfuran, 2-methylfuran, and furan, Combust. Flame 181 (2017) 251-269. 
[46] A.C. Davis, S.M. Sarathy, Computational study of the combustion and atmospheric decomposition of 2-methylfuran, J. Phys. Chem. A 117 (2013) 7670-7685.

[47] Y. Zhang, K.P. Somers, M. Mehl, W.J. Pitz, R.F. Cracknell, H.J. Curran, Probing the antagonistic effect of toluene as a component in surrogate fuel models at low temperatures and high pressures. A case study of toluene/dimethyl ether mixtures, Proc. Combust. Inst. 36 (2017) 413421.

[48] C. Lee, S. Vranckx, K.A. Heufer, S.V. Khomik, Y. Uygun, H. Olivier, R.X. Fernandes, Zeitschrift fur physikalische chemie-international journal of research in physical chemistry \& chemical physics, Z. Phys. Chem. 226 (2011) 1-27.

[49] C. Hemken, U. Burke, K.Y. Lam, D.F. Davidson, R.K. Hanson, K.A. Heufer, K. Kohse-Höinghaus, Toward a better understanding of 2butanone oxidation: Detailed species measurements and kinetic modeling, Combust. Flame 184 (2017) 195-207.

[50] C. Morley, GasEq. http://www.gaseq.co.uk.

[51] U. Burke, K.P. Somers, P. O'Toole, C.M. Zinner, N. Marquet, G. Bourque, E.L. Petersen, W.K. Metcalfe, Z. Serinyel, H.J. Curran, An ignition delay and kinetic modeling study of methane, dimethyl ether, 
and their mixtures at high pressures, Combust. Flame 162 (2015) 315330.

[52] D. Darcy, H. Nakamura, C.J. Tobin, M. Mehl, W.K. Metcalfe, W.J. Pitz, C.K. Westbrook, H.J. Curran, An experimental and modeling study of surrogate mixtures of $n$-propyl-and $n$-butylbenzene in $n$-heptane to simulate n-decylbenzene ignition, Combust. Flame 161 (2014) 14601473.

[53] S.M. Burke, U. Burke, R. Mc Donagh, O. Mathieu, I. Osorio, C. Keesee, A. Morones, E.L. Petersen, W. Wang, T.A. DeVerter, An experimental and modeling study of propene oxidation. Part 2: Ignition delay time and flame speed measurements, Combust. Flame 162 (2015) 296-314.

[54] C.J. Sung, H.J. Curran, Using rapid compression machines for chemical kinetics studies, Prog. Energy Combust. Sci. 44 (2014) 1-18.

[55] S.S. Goldsborough, S. Hochgreb, G. Vanhove, M.S. Wooldridge, H.J. Curran, C.J. Sung, Advances in rapid compression machine studies of low-and intermediate-temperature autoignition phenomena, Prog. Energy Combust. Sci. 63 (2017) 1-78.

[56] K.A. Heufer, H. Olivier, Determination of ignition delay times of different hydrocarbons in a new high pressure shock tube, Shock Waves 20 (2010) 307-316. 
[57] E.L. Petersen, R.K. Hanson, Nonideal effects behind reflected shock waves in a high-pressure shock tube, Shock Waves 10 (2001) 405-420.

[58] B. Esser, RWTH Aachen, (1991).

[59] K. Zhang, C. Banyon, J. Bugler, H.J. Curran, A. Rodriguez, O. Herbinet, F. Battin-Leclerc, C. B'Chir, K.A. Heufer, An updated experimental and kinetic modeling study of $n$-heptane oxidation, Combust. Flame 172 (2016) 116-135.

[60] D. Darcy, C.J. Tobin, K. Yasunaga, J.M. Simmie, J. Würmel, W.K. Metcalfe, T. Niass, S.S. Ahmed, C.K. Westbrook, H.J. Curran, A high pressure shock tube study of $n$-propylbenzene oxidation and its comparison with n-butylbenzene, Combust. Flame 159 (2012) 2219-2232.

[61] G. Blanquart, P. Pepiot-Desjardins, H. Pitsch, Chemical mechanism for high temperature combustion of engine relevant fuels with emphasis on soot precursors, Combust. Flame 156 (2009) 588-607.

[62] K. Narayanaswamy, G. Blanquart, H. Pitsch, A consistent chemical mechanism for oxidation of substituted aromatic species, Combust. Flame 157 (2010) 1879-1898.

[63] K. Narayanaswamy, P. Pepiot, H. Pitsch, A chemical mechanism for low to high temperature oxidation of $n$-dodecane as a component of transportation fuel surrogates, Combust. Flame 161 (2014) 866-884. 
[64] R. Tripathi, C. Lee, R.X. Fernandes, H. Olivier, H.J. Curran, S.M. Sarathy, H. Pitsch, Ignition characteristics of 2-methyltetrahydrofuran: an experimental and kinetic study, Proc. Combust. Inst. 36 (2017) 587595.

[65] L. Cai, H. Pitsch, S.Y. Mohamed, V. Raman, J. Bugler, H. Curran, S.M. Sarathy, Optimized reaction mechanism rate rules for ignition of normal alkanes, Combust. Flame 173 (2016) 468-482.

[66] K.P. Somers, J.M. Simmie, F. Gillespie, C. Conroy, G. Black, W.K. Metcalfe, F. Battin-Leclerc, P. Dirrenberger, O. Herbinet, P.A. Glaude, P. Dagaut, C. Togbé, K. Yasunaga, R.X. Fernandes, C. Lee, R. Tripathi, H.J. Curran, A comprehensive experimental and detailed chemical kinetic modelling study of 2,5-dimethylfuran pyrolysis and oxidation, Combust. Flame 160 (2013) 2291-2318.

[67] C.W. Bauschlicher Jr., The bond dissociation energies of 1-butene, Chem. Phys. Lett. 239 (1995) 252-257.

[68] Y.R. Luo, Comprehensive handbook of chemical bond energies, CRC press, (2007).

[69] J. Andrae, D. Johansson, P. Björnbom, P. Risberg, G. Kalghatgi, Co-oxidation in the auto-ignition of primary reference fuels and $n$ heptane/toluene blends, Combust. Flame 140 (2005) 267-286. 
[70] J.C.G. Andrae, T. Brinck, G.T. Kalghatgi, HCCI experiments with toluene reference fuels modeled by a semidetailed chemical kinetic model, Combust. Flame 155 (2008) 696-712.

[71] J.C.G. Andrae, P. Björnbom, R.F. Cracknell, G.T. Kalghatgi, Autoignition of toluene reference fuels at high pressures modeled with detailed chemical kinetics, Combust. Flame 149 (2007) 2-24.

[72] R. Minetti, A. Roubaud, E. Therssen, M. Ribaucour, L.R. Sochet, The chemistry of pre-ignition of $n$-pentane and 1-pentene, Combust. Flame 118 (1999) 213-220.

[73] S. Touchard, R. Fournet, P.A. Glaude, V. Warth, F. Battin-Leclerc, G. Vanhove, M. Ribaucour, R. Minetti, Modeling of the oxidation of large alkenes at low temperature, Proc. Combust. Inst. 30 (2005) 1073-1081.

[74] M. Mehl, G. Vanhove, W.J. Pitz, E. Ranzi, Oxidation and combustion of the $n$-hexene isomers: A wide range kinetic modeling study, Combust. Flame 155 (2008) 756-772.

[75] R. Bounaceur, V. Warth, B. Sirjean, P.A. Glaude, R. Fournet, F. BattinLeclerc, Influence of the position of the double bond on the autoignition of linear alkenes at low temperature, Proc. Combust. Inst. 32 (2009) 387-394.

[76] M. Mehl, W.J. Pitz, C.K. Westbrook, K. Yasunaga, C. Conroy, H.J. 
Curran, Autoignition behavior of unsaturated hydrocarbons in the low and high temperature regions, Proc. Combust. Inst. 33 (2011) 201-208.

[77] A. Bierbach, I. Barnes, K.H. Becker, Product and kinetic study of the $\mathrm{OH}$-initiated gas-phase oxidation of furan, 2-methylfuran and furanaldehydes at $\approx 300 \mathrm{~K}$, Atmos. Environ. 29 (1995) 2651-2660.

[78] E.R. Ritter, J.W. Bozzelli, THERM: thermodynamic property estimation for gas phase radicals and molecules, Int. J. Chem. Kinet. 23 (1991) $767-778$.

[79] S.W. Benson, Thermochemical kinetics, Wiley, (1976).

[80] S.M. Burke, J.M. Simmie, H.J. Curran, Critical evaluation of thermochemical properties of $\mathrm{C}_{1}-\mathrm{C}_{4}$ species: Updated group-contributions to estimate thermochemical properties, J. Phys. Chem. Ref. Data 44 (2015) 013101.

[81] W.H. Green, J.W. Allen, R.W. Ashcraft, G.J. Beran, C.A. Class, C. Gao, C.F. Goldsmith, M.R. Harper, A. Jalan, G.R. Magoon, D.M. Matheu, S.S. Merchant, J.D. Mo, S. Petway, S. Raman, S. Sharma, J. Song, K.M. Van Geem, J. Wen, R.H. West, A. Wong, H. Wong, P.E. Yelvington, J. Yu, RMG reaction mechanism generator version 3.3 $<$ http://rmg.sourceforge.net/ $>$.

[82] H. Pitsch, Flamemaster: A C ++ Computer Program for 0D Combustion and 1D Laminar Flame Calculations, (1993). 
[83] B.W. Weber, W.J. Pitz, M. Mehl, E.J. Silke, A.C. Davis, C.J. Sung, Experiments and modeling of the autoignition of methylcyclohexane at high pressure, Combust. Flame 161 (2014) 1972-1983.

[84] N. Peters, G. Paczko, R. Seiser, K. Seshadri, Temperature cross-over and non-thermal runaway at two-stage ignition of $n$-heptane, Combust. Flame 128 (2002) 38-59.

[85] U. Pfahl, K. Fieweger, G. Adomeit, Self-ignition of diesel-relevant hydrocarbon-air mixtures under engine conditions, Symp. (Int.) Combust. 26 (1996) 781-789.

[86] H.K. Ciezki, G. Adomeit, Shock-tube investigation of self-ignition of $n$ heptane-air mixtures under engine relevant conditions, Combust. Flame 93 (1993) 421-433.

[87] G. Mittal, M.P. Raju, C.J. Sung, CFD modeling of two-stage ignition in a rapid compression machine: Assessment of zero-dimensional approach, Combust. Flame 157 (2010) 1316-1324.

[88] W. Wang, Z. Li, M.A. Oehlschlaeger, D. Healy, H.J. Curran, S.M. Sarathy, M. Mehl, W.J. Pitz, C.K. Westbrook, An experimental and modeling study of the autoignition of 3-methylheptane, Proc. Combust. Inst. 34 (2013) 335-343.

[89] M. Mehl, J.Y. Chen, W.J. Pitz, S.M. Sarathy, C.K. Westbrook, An approach for formulating surrogates for gasoline with application toward 
a reduced surrogate mechanism for CFD engine modeling, Energy Fuels 25 (2011) 5215-5223.

[90] J.M. Simmie, Kinetics and thermochemistry of 2,5dimethyltetrahydrofuran and related oxolanes: Next next-generation biofuels, J. Phys. Chem. A 116 (2012) 4528-4538.

[91] L. Cai, A. Sudholt, D.J. Lee, F.N. Egolfopoulos, H. Pitsch, C.K. Westbrook, S.M. Sarathy, Chemical kinetic study of a novel lignocellulosic biofuel: di-n-butyl ether oxidation in a laminar flow reactor and flames, Combust. Flame 161 (2014) 798-809.

[92] D. Darcy, M. Mehl, J.M. Simmie, J. Würmel, W.K. Metcalfe, C.K. Westbrook, W.J. Pitz, H.J. Curran, An experimental and modeling study of the shock tube ignition of a mixture of $n$-heptane and $n$-propylbenzene as a surrogate for a large alkyl benzene, Proc. Combust. Inst. 34 (2013) 411-418. 